Spring 3-2021

\title{
Occupational Therapy's Role in Addressing Sexuality and Intimacy for Individuals with Progressive Neuromuscular Disorders
}

\author{
Lindsay N. Richards \\ University of St. Augustine for Health Sciences \\ DOI: https://doi.org/10.46409/sr.MIYJ4971
}

Follow this and additional works at: https://soar.usa.edu/capstones

Part of the Gender and Sexuality Commons, Nervous System Diseases Commons, and the Occupational Therapy Commons

\section{Recommended Citation}

Richards, L. N. (2021). Occupational Therapy's Role in Addressing Sexuality and Intimacy for Individuals with Progressive Neuromuscular Disorders. [Doctoral project, University of St Augustine for Health Sciences]. SOAR @ USA: Student Capstone Projects Collection. https://doi.org/10.46409/sr.MIYJ4971

This Capstone is brought to you for free and open access by the Student Research at SOAR @ USA. It has been accepted for inclusion in Student Capstone Projects by an authorized administrator of SOAR @ USA. For more information, please contact soar@usa.edu, erobinson@usa.edu. 
Occupational Therapy's Role in Addressing Sexuality and Intimacy for Individuals with Progressive Neuromuscular Disorders

\author{
Lindsay N Richards \\ Department of Occupational Therapy, University of St. Augustine for Health Sciences
}

A Capstone Presented in Partial Fulfillment

of the Requirement for the Degree of DOCTOR OF OCCUPATIONAL THERAPY

University of St. Augustine for Health Sciences

November 2020 
Occupational Therapy's Role in Addressing Sexuality and Intimacy for Individuals with Progressive Neuromuscular Disorders

Lindsay N Richards

Department of Occupational Therapy, University of St. Augustine for Health Sciences

has been approved

November 2020

APPROVED:

Susan MacDermott, OTD, OTR/L, Doctoral Coordinator

Becki Cohill, OTD, OTR/L, Doctoral Coordinator

Erin Schwier, EdD, OTD, OTR/L, Program Director

ACCEPTED AND SIGNED:

Susan MacDermott, $\begin{aligned} & \text { Digitally signed by yusan MacDermott, OTD, oTR/ } \\ & \text { DN: }: \text { nn=Susan MacDernott, OTD, OTR } L, 0,0 \text {, Ou, }\end{aligned}$

OTD, OTR/L

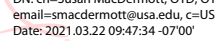

Susan MacDermott, OTD, OTR/L, Doctoral Coordinator Becki Cohill OTD OTR/L $/$ L

Becki Cohill, OTD, OTR/L, Doctoral Coordinator

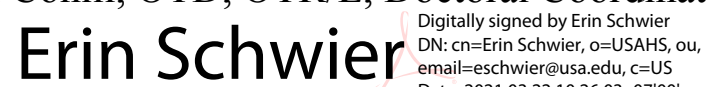
Date: 2021.03.22 10:26:03 -07'00'

Erin Schwier, EdD, OTD, OTR/L, Program Director 
Copyright (C) Lindsay Richards, 2020 all rights reserved 


\section{Table of Contents}

Chapter 1: Introduction ................................................................................................... 7

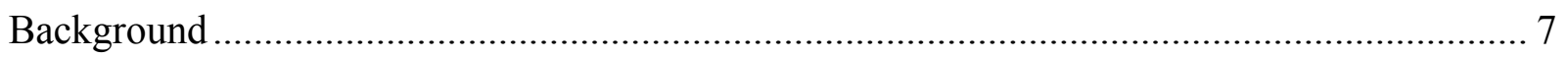

Statement of the Problem.......................................................................................... 10

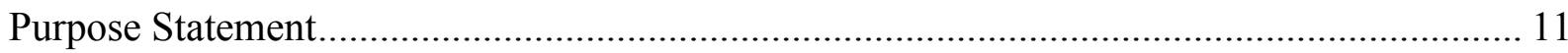

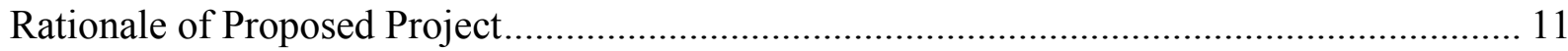

Significance of Proposed Project ............................................................................ 14

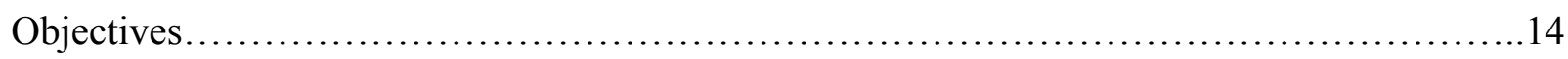

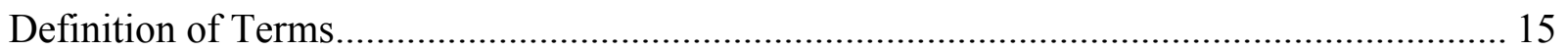

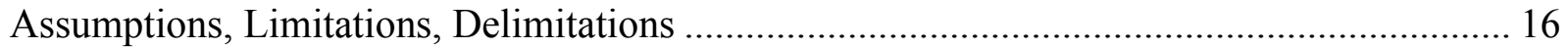

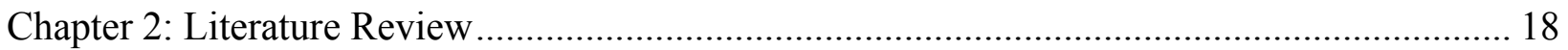

Disruptions in Sexual Occupations for Individuals with PND ........................................ 18

Effects of Caregiver Burden on Intimate Relationships ................................................ 20

Occupational Therapy's Role in Addressing Intimacy and Sexual Activity ......................... 21

Barriers to Healthcare Professional Involvement .............................................................. 22

Application of Theoretical Models on Intervention....................................................... 23

Literature Review Conclusion ............................................................................... 25

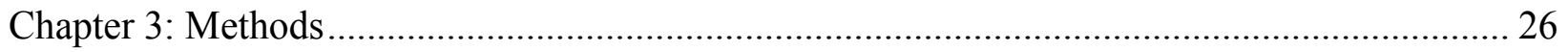

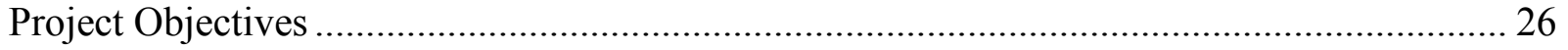

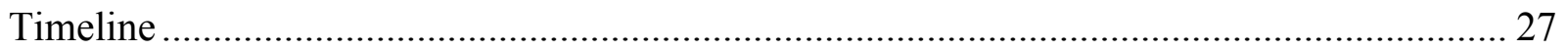




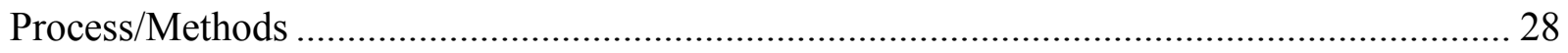

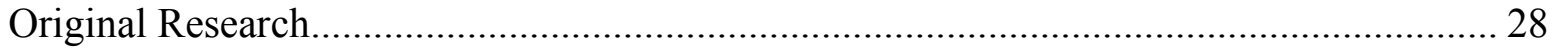

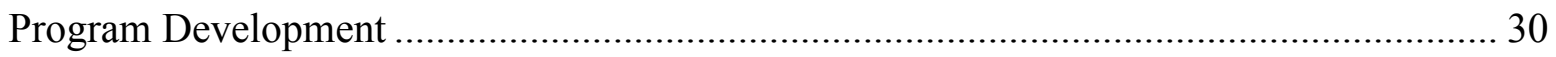

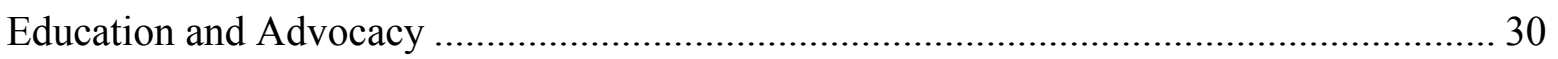

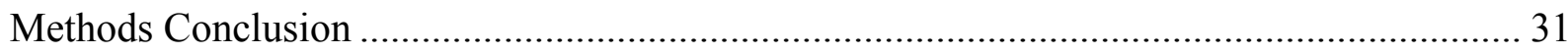

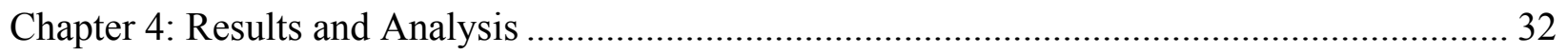

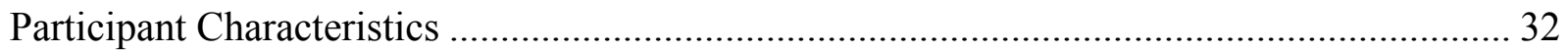

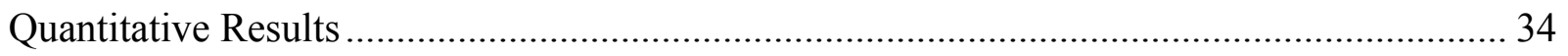

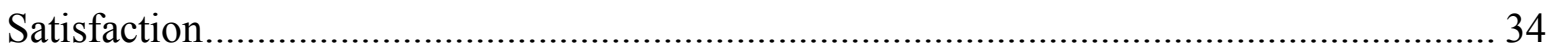

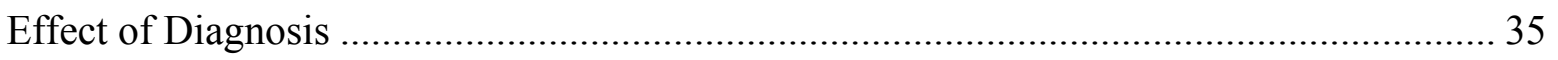

Current Sexual Health Care and Comfort ........................................................................ 37

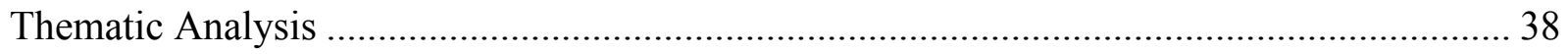

Physical Symptoms Impacting Quality of Sexual Activity .......................................... 39

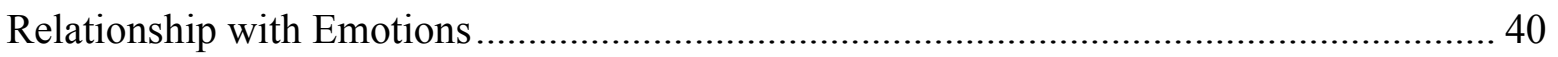

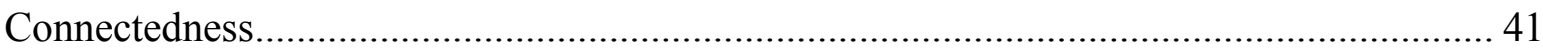

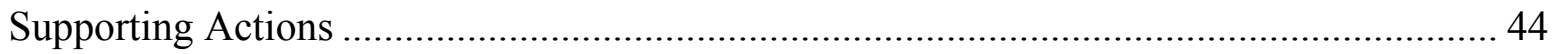

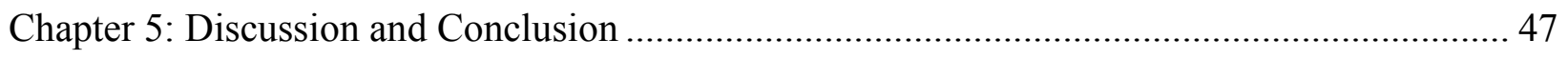

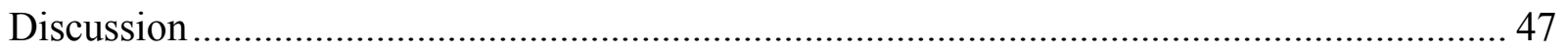

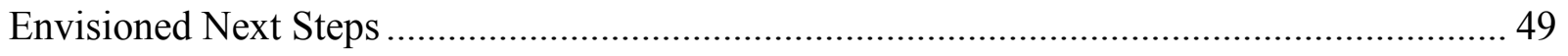

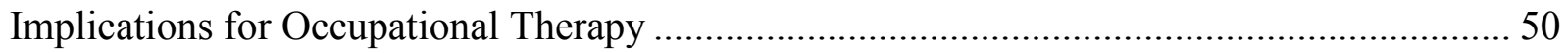




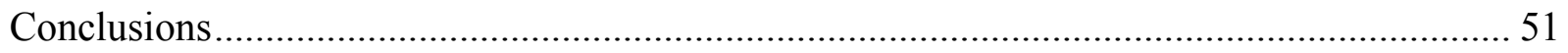

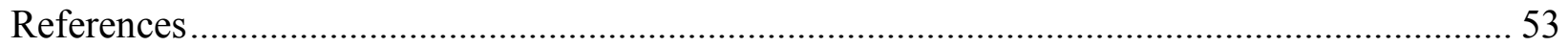

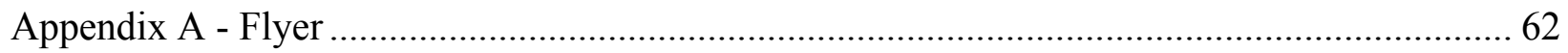

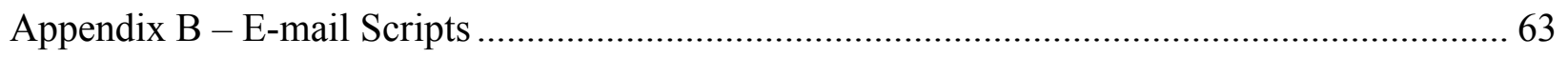

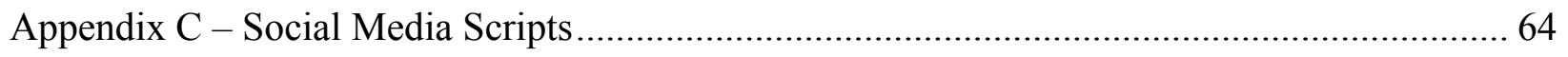

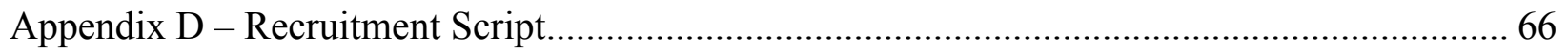

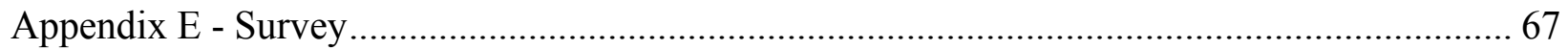

Appendix F - Sex and Intimacy in Gerontology Presentation ........................................... 73

Appendix G - Sex, Intimacy, and Assistive Technology Presentation .................................. 75 


\section{Occupational Therapy's Role in Addressing Sexuality and Intimacy for Individuals with Progressive Neuromuscular Disorders}

\section{Chapter 1: Introduction}

The purpose of this proposal is to outline background information and to provide rationale for my capstone project regarding occupational therapy's role in addressing intimacy and sexuality in individuals with progressive neuromuscular diseases (PND).

\section{Background}

Parkinson's disease (PD), Multiple Sclerosis (MS), Huntington's Disease (HD), and Amyotrophic Lateral Sclerosis (ALS), also known as motor neuron disease or Lou Gehrig's disease, are progressive neurological illnesses that affect the muscular system (McCabe et al., 2009). These four diagnoses can be referred to as progressive neuromuscular disorders and will be collectively referred to as PND in this manuscript. Approximately $63 \%$ of individuals with MS and $70-80 \%$ of individuals with PD report being affected by sexual problems (National Multiple Sclerosis Society, n.d.; Dolhun, n.d.). Similarly, research has also indicated that individuals with Huntington's disease and individuals with ALS experience changes in sexual ability and relationships (Mayers \&. Heller, 2003; Poletti et al., 2019). These changes can include decreased libido, erectile dysfunction, dyspareunia, and sexual dissatisfaction (Bronner et al., 2004). Various physical, psychological, and social factors are affected in individuals with PND and can lead to changes in sexual function (Mackett, 2016).

Individuals who carry these diagnoses can have many motor symptoms present such as: rigidity, tremors, atrophy, akinesia, chorea, fatigue, speech impairments, postural changes, and decreased fine and gross motor control (Bronner et al., 2004; Dehghan-Nayeri et al., 2017; 
Mayer \& Heller, 2003; McCabe et al., 2009; Verschuren et al., 2010). These changes in motor ability often have a negative impact on their personal relationships; specifically, sexual activity and intimacy (Verschuren et al., 2010). In addition to these symptoms affecting their sexual health, they often require assistance to complete other ADLs which can lead to negative psychological changes in both the individual with a PND and their partners (Mosley et al., 2017; Oh \&. Schepp, 2013).

When social intimacy is ignored, it can have detrimental consequences on quality of life, such as psychological factors related to lowered self-esteem and changes in mood (National Multiple Sclerosis Society, n.d.). Progressive neuromuscular diseases can often lead to neuropsychiatric symptoms including depression, anxiety, apathy, dysphoric mood, and cognitive fatigue (Aarsland et al., 2009; Aubeeluck et al, 2012; Levenson et al., 2014). Furthermore, there is a large body of evidence linking sexuality and intimacy to quality of life and well-being (Diamond \& Huebner, 2012; Poletti et al., 2018). Emotional and physical intimacy are fundamental aspects for an individual's well-being and overall quality of life (World Parkinson Coalition, 2017). Promoting social interaction through open communication to help foster and strengthen healthy intimate relationships can be an effective way to target these psychosocial aspects (Babaee \& Ghahari, 2016).

Caregiver burden refers to the array of difficulties that ensue as a result of providing care to a person with an illness or a disability (Martinez-Martin et al., 2012). The progressive nature of neuromuscular disorders means that the need for care is continually changing and increasing. Increased care responsibilities can lead to feelings of frustration, sadness, resentment, anger, and a worry for the future (Vatter et al., 2018). Improving and promoting open communication, selfdisclosure, problem solving, and empathic response skills can enhance and strengthen the 
intimate relationship (Kardan-Souraki et al., 2015). Including partners in interventions and focusing on each unique relationship can be more beneficial to individuals diagnosed with chronic illnesses (Chawla \& Kafescioglu, 2012).

Though altered sexual and intimate abilities is a huge concern for the individuals facing it, a vast majority of healthcare professionals are not proactively discussing health-related issues regarding sexuality and intimacy with their patients (Kardan-Souraki et al., 2015; Dyer \& das Nair, 2013). Seventy-three percent of individuals with neurological disorders reported that they did not discuss with any health professional the impact that their symptoms had on their intimate relationships (Mackett, 2016). Even though the demand for healthcare professionals to address sexual health is present, these professionals report many perceived barriers to discussing sexuality. These barriers include lack of knowledge, personal discomfort with discussing the subject, and the view that care relating to sexual health is not their responsibility (Pieters et al., 2018). Often times professionals are equipped with knowledge of the physiological aspects of sexuality but have no training on clinical implementation of this knowledge (Pieters et al., 2018). Comfort level varies from person to person, but a lack of comfort has been shown to have a negative impact on the willingness to discuss sexual health issues (Haboubi \& Lincoln, 2003). In order to ensure people are receiving adequate support in the area of sexual health it is important that more focus be shifted to this important area of occupation.

The occupations of sexual activity and social participation are addressed in the framework and are within the scope of practice for occupational therapy (American Occupational Therapy Association, 2014). Occupational therapists (OT) play an important role in addressing intimacy as they have a unique skill set that allows them to address sexual concerns through functional, individualized interventions, and task analysis. Sexual activity is an activity of daily 
living (ADLs) that needs to be addressed as part of a holistic approach to treating the whole person (American Occupational Therapy Association [AOTA], 2013). Concerns related to sexuality and relationships can be addressed through positioning, task and tool adaptation, energy conservation strategies, and other forms of intervention familiar to occupational therapists (Rose \&. Hughes, 2018). As previously stated, it is important that the partners also be included as this will support positive engagement and facilitate application of therapeutic interventions within their own intimate social context.

Though there is a clear need for occupational therapy intervention in this domain, professionals often exclude sexuality from everyday practice (McGrath \& Sakellariou, 2015). Therapists often avoid mention of sexual activity and intimacy due to the sensitive nature of the topic, lack of education, the assumption that the topic is handled by other healthcare professionals, and lack of time within treatment sessions (Hattjar, 2017). The high prevalence, broad diversity of sexual problems, and impact on the well-being of both the individual with PND and their spouse indicate that addressing this area of occupation is essential (Hees et al., 2017).

\section{Statement of the Problem}

Adults with PND face many challenges related to intimacy and sexual activity and there currently are a limited number of healthcare professionals addressing this sensitive subject (Mackett, 2016). Occupational therapists must enhance their role in providing these individuals with the education and resources to maintain sexual relationships that are healthy and also take into consideration the strengths and limitations of each individual. 


\section{Purpose Statement}

The purpose of this project is to examine the experience of adults with PND as sexual and intimate beings in the context of their personal relationships and implement a skilled occupational therapy program to address sexual and intimate participation to enhance meaningful relationships.

\section{Rationale of Proposed Project}

An exploration of the experiences of adults with PND and the potential role of OT will enhance meaningful participation in relationships for this population. Due to the complex impact a PND can have on an individual, several frames of references (FOR) and models can be applied to inform occupational therapy intervention when addressing intimacy.

\section{Ex-PLISSIT Model Application}

The Ex-PLISSIT model is an extension of the PLISSIT model that can be used as a guide for intervention in addressing the sexual health needs of individuals with PND (Taylor \& Davis, 2006). This model consists of numerous stages of intervention-permission, limited information, specific suggestions, and intensive therapy (Taylor \& Davis, 2006). The first stage is the permission-giving stage in which participants are given the opportunity to express their concerns/fears about sexuality and sexual activity (Taylor \& Davis, 2006). In order for occupational therapy practitioners to continue with treatment it is important to look at the concerns that each individual faces in order for intervention to remain client-centered. The second stage is the limited information stage, in which education is given on the impact of illness on sexuality and the effects of treatments on sexual function (Taylor \& Davis, 2006). This would include education on sex specific problems such as erectile dysfunction, impaired sex drive, and reduced libido (Hees et al., 2017). However, this can also include other physical barriers like 
fatigue, tremors, weakness, or medication schedules (Forwell et al., 2014). The third stage is the specific suggestions stage, in which potential solutions can be offered in order to enhance individual's participation in their sexual relationships (Taylor \& Davis, 2006). Occupational therapists play a vital role at this stage as they can use their expertise of task analysis in order to make suggestions based on specific strengths, limitations, and social contexts. The fourth stage is the intensive therapy stage, in which resources can be provided if an individual could benefit from a referral to occupational therapy (Taylor \& Davis, 2006).

\section{Occupational Adaptation Model Application}

Occupational adaptation is a model that focuses on the interactive process between an individual and their occupational environment and includes modifying environments or tasks to increase participation in meaningful occupations (Schkade \& Schultz, 1992). This model can be applied when an individual's typical response no longer meets the challenges of an occupation and now has to modify the task or their behavior in order to achieve a successful outcome. There are many methods to modifying activities including compensatory strategies, assistive devices, and energy conservation techniques. Examples of modifications may include resting prior to dates for those with poor endurance; placing pillows under stiff or painful joints; or organizing daily routines to allow for more quality time with their partner (AOTA, 2013). Activity adaptation and energy conservation strategies are important as they promote continuing participation in essential occupations by reducing physical demands and conserving energy. As it pertains to this program, education on various strategies will aid in individuals being able to adapt different activities or routines to allow for positive sexual interactions with their partners. 


\section{Cognitive Behavioral Frame of Reference Application}

The cognitive behavioral FOR should be considered as it is focused on the psychological barriers to engagement in meaningful occupations. As previously mentioned, both the individual with a PND and the partner often go through psychological changes that affect their relationship. Past studies have shown positive effects of CBT in individuals with sexual dysfunctions (Adam et al., 2019).This FOR addresses self-regulation, self-efficacy, self-awareness, and insight (Bandura, 1985). Self -regulation is important to address in both the individual with a PND and the individual's partner, as therapists can introduce strategies to help manage stress and regulate emotions. It will be important that the program addresses self-efficacy and empowers individuals to believe in themselves and their ability to effectively participate in their desired occupations and in their relationship. A large portion of this program with be devoted to self-awareness and having realistic expectations of oneself and one's partner stripped from inaccurate and misinformed messaging around sexuality and intimacy.. In order to facilitate positive interactions, it is important that both parties have a realistic understanding of their strengths and weaknesses and how that effects their functional ability. Self-awareness serves as the basis for insight, which involves the understanding of the change's happening in one's abilities. Insight is vital as it is needed to reframe attainable goals and standards for functioning in one's relationship. Social and life skills groups are forms of interventions outlined in this FOR. As it pertains to this program, occupational therapists can include empathetic and productive conversations skills, as well as verbal and nonverbal communication skills to encourage positive engagement in relationships. 


\section{Significance of Proposed Project}

Ensuring that individuals are comfortable and content with their intimate relationships is of utmost importance. It is important that occupational therapists address the social skills, motor skills, and processing skills that are affected when a person has a PND. Occupational therapists have the ability to encourage individuals and their partners to reconceptualize sexual activity and sexuality in order to explore new possibilities for sexual expression (Solet, 2014). The significance of this proposed capstone is to promote fulfilling and meaningful participation in relationships for people living with PND by addressing intimacy, sexual activity, and individual components of building and maintaining a healthy relationship. This program is also significant as it relates to the profession of occupational therapy as it can improve comfort and confidence in addressing sexual occupations.

\section{Objectives}

\section{Learning Objectives}

- To determine current literature on the effects of progressive neuromuscular disorders on sexual activity and intimacy

- To identify literature on OT's role in intimacy and sexual activity

- To evaluate results of literature on effective interventions addressing various performance skills for individuals with PND

\section{Outcome Objectives}

- Survey individuals with PND and their partners in order to identify areas of unmet need

- Survey individuals with PND and their partners in order to identify recommendations to inform programing 
- Interview or observe various professionals (i.e. occupational therapists, neurologists, sex therapists/counselors) currently specializing in addressing sexuality and intimacy to determine how intimacy and sexual activity are currently being addressed

- Hold focus groups to gain feedback to guide modification to the current program

- To modify the current program and develop a detailed proposal addressing and promoting meaningful intimate and sexual relationships for individuals with PND

- Educate and advocate for occupational therapy's role in addressing sexuality

\section{Definition of Terms}

Intimacy will refer to physical, emotional, experiential, and intellectual interactions with partners that require mutual vulnerability, communication, knowledge, acceptance, and understanding ("Intimacy”, 2019; The Institute for Sex, Intimacy and Occupational Therapy, n.d.). Intimacy can take on many forms and does not have to include sexual activity.

Sexual activity will refer to sexual experiences engaged in with self or others that can result in fulfillment, affirmation, satisfaction, relaxation, discontent, and/or remorse (The Institute for Sex, Intimacy and Occupational Therapy, 2020).

Caregiver burden will refer to the negative psychological state that occurs in caregivers by the demands of providing care to a person with an illness or disability (Mosley et al., 2017).

Progressive neuromuscular disorders will refer to chronic disorders that attack the nervous system and result in nerve and muscle impairments and will worsen over time (Mayo Clinic, 2020). The disorders covered in this proposal will include Parkinson's Disease (PD), Multiple Sclerosis (MS), Huntington's Disease (HD), and Amyotrophic Lateral Sclerosis (ALS). 


\section{Assumptions, Limitations, Delimitations}

It is important to acknowledge areas of assumption related to this project as well as the literature that supports the need for a program of this kind. Limitations and delimitations exist that could potentially influence the outcomes of this project. These constraining factors exist both internally and externally and are within varying degrees of control.

An underlying assumption is that individuals with PND have a need for a program addressing intimacy and sexual activities. This leads to another assumption that disruptions in intimacy will have a negative impact on sexual occupations. There is an abundance of literature on caregiver burden and the negative effects this can have on relationships, so it is assumed this may carry into intimacy and sexual activity. Another assumption is that this area of focus is not being addressed by other healthcare professionals. Addressing various domains of sexual health is within the scope of other professions such as nurses, medical staff, psychologists, physiotherapists, social workers, and occupational therapists (O’Connor et al., 2019). However, occupational therapy's distinct role is clearly represented by focusing on sexual activity and intimacy as it translates to numerous areas of occupation considering the unique contexts of each individual.

A limitation of this project is that individuals may choose not to participate due to the sensitive nature of the topic. Some individuals may not want to describe the intimate details of their relationships or discuss difficulties they may be facing. Therapeutic use of self will serve a vital tool to build rapport with the couples as this may increase comfort and willingness to share. Another limitation is that the setting may be unintentionally restrictive to the severity of symptoms. This program will take place in an outpatient setting, and it is unlikely for individuals with PND who have more severe deficits to attend outpatient therapy. 
Delimitations of this project include the chosen setting and participant population. An outpatient setting was chosen as patients receiving this type of service would be the most medically stable. Intimacy and sexual activity should not be ignored or unaddressed in any setting; however, the sessions outlined in this program require a certain degree of medical stability in order to participate. Individuals with PD, MS, HD, and ALS were chosen as these are all progressive neuromuscular diseases. There are other neuromuscular diagnoses that could potentially benefit from a program of this kind but given the limited time and resources it was necessary to narrow down the focus. Another delimitation is that this program is designed for individuals who are in relationships. The choice to include partners was made due to the dense literature on the negative impacts of caregiver burden on caregiving partners. 


\section{Chapter 2: Literature Review}

There is vast literature supporting the need for addressing intimacy and sexual participation in individuals with progressive neuromuscular disorders (PND). These individuals face not only the physical and motor challenges, but many psychosocial changes that interrupt their occupational performance in sexual occupations. In addition, partners often take on the role of caregiver which further exacerbates the lack of intimacy in their relationships. Occupational therapists are well-equipped to handle the multi-faceted challenges these individuals face, yet they are rarely utilized. The aim of this review is to provide in-depth analysis of current research, theoretical foundation, as well as gaps in the literature,

\section{Disruptions in Sexual Occupations for Individuals with PND}

As previously stated, individuals with PD report many sexual problems as a result of their motor and nonmotor symptoms. Nonmotor symptoms such as depression, anxiety, and sensory changes result in decreased sexual desire, cessation of sexual activity, and decreased frequency and intensity of orgasm (Bronner, 2011). Motor symptoms such as rigidity, tremors, bradykinesia, and impaired fine motor control result in impaired intimate touch, sexual passivity, need for changes in sexual habits and positioning, and feeling less attractive (Bronner, 2011). In a study examining personal sexual practice and function, individuals with PD showed more dissatisfaction with their current sex life than healthy controls (Jacobs et al. , 2000). Common treatments, such as dopamine agonist medications have an effect on behaviors related to sexuality and have shown to have negative effects on relationships with partners (Rees et al., 2007). Though these individuals report a high frequency of sexual dysfunction, a majority of individuals with PD reported not having discussed sexual issues with their partners (Bronner et al., 2004). 
In patients with MS fatigue, depression, anxiety about incontinence, and spasticity can contribute to disrupted sexual activity (Rees et al., 2007). The National Multiple Sclerosis Society (n.d.) states that $63 \%$ of individuals with MS have reported a decline in sexual activity since their diagnosis. This decline can lead to decreased quality of life, loss of self-esteem, anger, and other emotional changes (National Multiple Sclerosis Society, n.d.). As this disease progresses, lower satisfaction with sexual function and a lack of sexual interest have been reported (Calabrò et al., 2018; Marck et al., 2016). As with PD, individuals with MS would benefit from further studies examining quality of life and qualitative information about their perception of occupational deficits in sexual activity and intimacy.

Little research was found focusing on intimacy and sexuality in individuals with HD. However, Mayers \& Heller (2003) call to attention many symptoms that may affect performance in sexual occupations such as impairments in communication skills and speech initiation, loss of bowel and bladder function, and inability to control fine and gross movements due to chorea (uncoordinated, rapid jerking movements). Furthermore, this study contained interviews of individuals with late stage HD and the following themes were found (Mayers \& Heller, 2003):

- Almost half of the participants expressed interest in discussing sexuality issues

- The absence of intimacy and sexuality represented a significant loss

- A loss of sense of being sexually appealing or able

- The need for awareness and sensitivity

Though there is limited research in this area, due to the parallels in symptoms of the previously mentioned diagnoses it is assumed individuals with HD face similar barriers in sexual occupations. 
In ALS, skeletal muscle weakness, changes in body image, poor self-esteem, and depression can impact sexuality and intimate relationships (Poletti et al., 2018). O'Connor et al. (2009) describe fear of rejection and not satisfying their partner as being psychological barriers that can affect intimacy and relationships. As ALS progresses individuals often need assistive equipment which can negatively impact communication as well as emotional and physical connection (Taylor, 2011). Numerous studies have shown that sexuality is an important aspect of well-being and quality of life in ALS that is negatively affected (O'Connor \& McCabe, 2011; Poletti et al., 2018; Wasner et al., 2004). Though there is research presenting domains that can have an effect on intimacy, there is a gap present as it related to qualitative perspectives and their perception of barriers.

\section{Effects of Caregiver Burden on Intimate Relationships}

Caregiver burden is a negative state induced by the demands of providing care to an individual with a disability (Mosley et al., 2017). Due to the progressive nature of these disorders the demands of caregiving partners increase as the disease advances into later stages. In a study evaluating quality of life in individuals with PD and their caregiving spouses, both partners reported significant decreases compared to before the onset of disease as well as increased burden of care with worsening disease severity (Martinez-Martin et al., 2012). In a study evaluating female caregiving spouses experience it was found that there was an increase in negative feelings such as resentment, frustration, disappointment, guilt, distress, and apprehension about providing care as their partner's disease progressed (Vatter et al., 2018). This study contained the following quote from a caregiving partner about their feelings on their role transition as cognitive symptoms declined: "I've just got this person that needs looking after, I haven’t gotten erm, a husband as such or a partner or a friend even..." (Vatter et al., 2018, p. 
607). Little information was found about caregiving partners of individuals with HD. However, Aubeeluck et al. (2011) reported the effects of caregiving for individuals with HD as experiencing feeling loss of emotional closeness, isolation and loneliness, neglected personal needs, a sense of loss, and not feeling socially supported. In caregiving partners of individuals with ALS, numerous studies have identified burden of care as having a negative impact on relationships due to high level of distress in caring for their partner, perceptions of a loss of intimacy, the presence of limitations secondary to the disease, and the struggle of dealing with anger and frustration (Goldstein et al., 2006; Oyebode et al., 2013; Poletti et al., 2018). Though there are many studies on the effects of caregiver burden a gap in the literature exists as this relates directly to sexual occupations across a variety of progressive neuromuscular diagnoses.

\section{Occupational Therapy's Role in Addressing Intimacy and Sexual Activity}

Sexual activity is listed as an activity of daily living in The Occupational Therapy Practice Framework: Domain and Process 3rd Edition (American Occupational Therapy Association [AOTA], 2014). In order to remain client-centered it is important that occupational therapists are well-versed in all occupations that are meaningful to their clients, yet sexual occupations often go unaddressed (McGrath \& Lynch, 2014). Occupational therapists are equipped with the knowledge to address sexual concerns through positioning, energy conservation strategies, tool adaptation, modifications to the environment or routines, or restoration of impaired performance skills impacting sexual activity (Rose \&. Hughes, 2018; AOTA, 2013). To support individuals with disabilities in identifying issues related to their occupational performance in sexual occupations it is vital that occupational therapists give clients opportunities to discuss any sexual concerns they may have (McGrath \& Sakellariou, 2016). Furthermore, occupational therapists may have more opportunities to discuss intimacy 
due to their professional role of addressing intimate care during activities of daily living (Lichtenberg, 2014). Due to occupational therapists' focus on occupations in natural contexts, they have unique skills that could assist individuals with successful performance in intimate and sexual occupations. Though there is literature to support the use of occupational therapists in addressing sex and intimacy, there is limited information on applying this to the population of individuals with PND.

\section{Barriers to Healthcare Professional Involvement}

Though there is a large body of evidence linking sexuality and intimacy to well-being and quality of life, it continues to be unaddressed by healthcare professionals (Diamond \& Huebner, 2012). According to a systemic review by Dyer \& das Nair (2012) and a study by Haboubi \& Lincoln (2003) surveying nurses, doctors, physiotherapists, and occupational therapists, the following themes were identified in regard to why this important domain is not being addressed:

- Fear about 'opening a can of worms' and not having time and resources to address these complex issues

- Worry about causing offense to the patient

- Concerns about knowledge limitations and lack of awareness

- Lack of resources, time, and training, and poor opportunities for future training

- Personal discomfort with the subject

- Lack of awareness of sexual issues

These themes clearly outline a need for change regarding addressing sexual needs, and the majority of healthcare professionals agreed that in order to provide holistic care sexual issues need to be addressed (Haboubi \& Lincoln, 2003). In a qualitative study exploring attitudes toward sexuality and disability findings indicated individuals with disabilities are often viewed 
as asexual, there is a lack of emphasis on sexual rights, and there is a lack of sexual education and knowledge surrounding sexuality and disability (Esmail et al. , 2010).

\section{Application of Theoretical Models on Intervention}

Cognitive Behavioral Therapy (CBT) has been studied in various domains that could indicate its use for addressing sexual occupations. In individuals with PD, CBT techniques have included; cognitive restructuring for depressed mood, increased meaningful leisure activities to improve loss of interest, relaxation techniques for sleep disturbance, problem solving for physical limitation throughout the day, energy conservation and pacing for fatigue, and setting realistic goals for concentration (Dobkin et al., 2008). In order to address impaired communication skills and negative thought patterns in caregiving partners of individuals with PD, CBT techniques can be beneficial to guide intervention. In a randomized-control trial examining the use of CBT versus a non-treatment control group, caregivers receiving CBT showed a significant decrease in caregiver burden and caregiver strain that persisted at a three month follow up (Secker \& Brown, 2005). The CBT interventions focused on the following: education on CBT, accessing support and resources within the community, leisure and self-care activity scheduling, relaxation training, challenging negative thoughts, challenging maladaptive rules, and planning for the future (Secker \& Brown, 2005). Similarly, in individuals with MS, CBT has been used to combat emotional and mental challenges and decrease emotional stress by identifying and shifting negative beliefs and behaviors (Beier, n.d.). Little research was found in using CBT for caregivers of those with MS but the principles of CBT may be applicable to the psychosocial challenges caregiving partners may be facing. In searching the literature for CBT interventions in those with HD and ALS, systematic reviews and meta-analyses have cited a gap in the literature related to cognitive behavioral interventions and a need for more high quality 
methodology (Clare et al., 2019; Ghielen et al., 2019). Though this gap exists, it is assumed cognitive behavioral interventions would have similar affect due to the congruences in psychosocial changes in these diagnoses.

There is little known research utilizing CBT to address negative thoughts, feelings, and behaviors as they relate to sexuality and intimacy. Though there is evidence in support of the use of CBT in caregivers, little research exists as it relates to intimacy in. caregiving partners. Wetterneck \& Hart (2012) argue that CBT fails to address individual therapy, they present behaviorally based therapy to promote functional interpersonal skills. The information from this article does support further research in specifically addressing intimacy using CBT as there is not enough empirical data at this time to negate the use of these techniques. Combining CBT techniques with models that focus on behaviors promoting sexual well-being could be beneficial to addressing these unmet needs.

Integrating the extended PLISSIT (Ex-PLISSIT) model as a basis for intervention can be effective in assisting and meeting sexual needs for individuals with PND. The original PLISSIT model developed by Annon (1976) has been widely used in healthcare for the past 30 years (Taylor \& Davis, 2006). However, Taylor and Davis (2006) have extended this model to form the Ex-PLISSIT model, which emphasizes giving permission to discuss their needs at all stages. In patients with chronic illness, like those with PND, the extension of the permission-giving stage offers more opportunity for reflection on specific intervention strategies (Taylor \& Davis, 2006). In turn, occupational therapy practitioners can then use the information learned from this reflection to develop their practice to better serve individuals with PND.

McGrath and Sakellariou (2016) describe the use of the PLISSIT model in occupational therapy as the following: developing trainings regarding sexuality that address values and 
beliefs, providing knowledge about occupational therapy's scope of practice in relation to sexual occupations, and increase awareness of interventions that can support clients in sexual problem areas. In a randomized-control trial examining the use of the Ex-PLISSIT model for married women with MS there were significant improvements in various domains of sexual dysfunction (Daneshfar et al., 2017). Hattjar (2017) also outlines methods for addressing intimacy and sexual activity using a combination of the PLISSIT model as well as The Intentional Relationship Model. The Intention Relationship Model is used to build a therapeutic relationship based on empathy, ethics, compassion, courtesy, and respect (Hattjar, 2017). This model will be useful with this population as it emphasizes a collaborative and client-centered approach that uses clinical reasoning and narrative throughout the therapeutic relationship (Taylor, 2008).

\section{Literature Review Conclusion}

The literature supports a need for increased involvement of healthcare professionals in addressing various aspects of sexual activity and intimacy. Intimacy and sexual activity are complex occupations that require various prerequisite motor, social, and processing skills that are interrupted in individuals with PND. Occupational therapists are equipped with a unique skill set that allows improvement in sexual occupations through adaptive strategies, task modifications, and psychosocial interventions in a meaningful way that takes into consideration the needs of individuals with PND and their partner. There is support for further research due to the current gaps in direct relation to intimacy and sexual participation. Occupational therapists must increase their role in addressing sexual occupations as they relate to the individual as well as their partner. 


\section{Chapter 3: Methods}

The purpose of this capstone is to examine the lived experience of individuals with PND and their partners in order to create a program that addresses occupational deficits in intimacy and sexual participation. Progressive neuromuscular disorders impact a variety of motor and social skills and often have a negative effect on an individual's ability to engage in intimate relationships (Mosley et al., 2017; Verschuren et al., 2010). Occupational therapists play a key role in addressing sexual concerns through individualized therapeutic interventions that take into consideration the individuals' strengths, weaknesses, preferences, and relational contexts. Though OT's have an inherent responsibility to address sexual occupations due to the holistic nature of their profession, they are often underutilized. This study aims to identify barriers and concerns that individuals with PND and their partners face regarding sexual and intimate occupations and recommendations for programming to address these limitations. This will inform occupational therapy practitioners on interventions for enhancing occupational performance in intimacy and sexual activity (AOTA, 2013; McGrath \& Sakellariou, 2015). This project also aims to increase knowledge of OT's role in addressing sexuality through various social media platforms and OT student courses.

\section{Project Objectives}

- Conduct online surveys to identify 1) barriers and concerns related to satisfying sexual and/or intimate relationships, 2) recommendations and insight to inform programming

- Integrate identified themes from survey into a program proposal addressing intimacy and sexual activity

- Educate on OT's role in addressing sexuality through social media and OT student courses 


\section{Table 1}

\section{Timeline}

\begin{tabular}{|c|c|c|c|c|c|c|c|c|c|c|}
\hline Task & Week 1 & Week 2 & Week 3 & Week 4 & Week 5 & Week 6 & Week 7 & Week 8 & Week 9 & Week 10 \\
\hline \multicolumn{11}{|l|}{$\begin{array}{l}\text { Become familiar with the } \\
\text { population by researching online } \\
\text { formal and informal sources }\end{array}$} \\
\hline \multicolumn{11}{|l|}{$\begin{array}{c}\text { Become familiar with OT } \\
\text { interventions related to sex and } \\
\text { intimacy }\end{array}$} \\
\hline \multicolumn{11}{|l|}{$\begin{array}{l}\text { Contact various organizations } \\
\text { about potential collaborations }\end{array}$} \\
\hline \multicolumn{11}{|l|}{$\begin{array}{l}\text { Identify and contact various } \\
\text { support groups about posting } \\
\text { survey and recruitment }\end{array}$} \\
\hline \multicolumn{11}{|l|}{$\begin{array}{l}\text { Attend support groups to become } \\
\text { familiar with population }\end{array}$} \\
\hline \multicolumn{11}{|l|}{$\begin{array}{l}\text { Recruit survey participants } \\
\text { through support groups and social } \\
\text { media postings }\end{array}$} \\
\hline \multicolumn{11}{|l|}{ Organize survey data } \\
\hline $\begin{array}{l}\text { Create presentations and present } \\
\text { on OT's role in addressing sex and } \\
\text { intimacy to OT students }\end{array}$ & & & & & & & & & & \\
\hline
\end{tabular}

\begin{tabular}{|c|c|c|c|c|c|c|c|c|c|c|}
\hline Task & Week 11 & Week 12 & Week 13 & Week 14 & Week 15 & Week 16 & Week 17 & Week 18 & Week 19 & Week 20 \\
\hline $\begin{array}{l}\text { Become familiar with the } \\
\text { population by researching online } \\
\text { formal and informal sources }\end{array}$ & & & & & & & & & & \\
\hline $\begin{array}{c}\text { Become familiar with OT } \\
\text { interventions related to sex and } \\
\text { intimacy }\end{array}$ & & & & & & & & & & \\
\hline $\begin{array}{l}\text { Contact various organizations } \\
\text { about potential collaborations }\end{array}$ & & & & & & & & & & \\
\hline $\begin{array}{l}\text { Identify and contact various } \\
\text { support groups about posting } \\
\text { survey and recruitment }\end{array}$ & & & & & & & & & & \\
\hline $\begin{array}{l}\text { Attend support groups to become } \\
\text { familiar with population }\end{array}$ & & & & & & & & & & \\
\hline $\begin{array}{c}\text { Recruit survey participants } \\
\text { through support groups and social } \\
\text { media postings }\end{array}$ & & & & & & & & & & \\
\hline Organize survey data & & & & & & & & & & \\
\hline $\begin{array}{l}\text { Create presentations and present } \\
\text { on OT's role in addressing sex and } \\
\text { intimacy to OT students }\end{array}$ & & & & & & & & & & \\
\hline $\begin{array}{c}\text { Identify themes and summarize } \\
\text { survey data }\end{array}$ & & & & & & & & & & \\
\hline $\begin{array}{c}\text { Create program proposal based on } \\
\text { survey data }\end{array}$ & & & & & & & & & & \\
\hline $\begin{array}{l}\text { Create research poster to } \\
\text { summarzie and present } \\
\text { information and results and } \\
\text { educate on OT's role }\end{array}$ & & & & & & & & & & \\
\hline
\end{tabular}




\section{Process/Methods}

This first portion of this project will involve (1) conducting original research in order to (2) create a detailed proposal for an occupational therapy program addressing intimacy and sexual activity. The second portion of this project will be focused on educating and advocating for OT's role in addressing sex and intimacy.

\section{Original Research}

Research Question. This project aims to answer the research question: What are the perceived impacts, barriers, and supports of PND on intimacy and sexual activity in individuals with PND and their partners?

Participants and Recruitment. This study will include adults with PD, MS, HD, and ALS and their partners over the age of 18. Participants will be recruited through a variety of organizations and social media groups that serve individuals with these diagnoses. Social media platforms that will be used for recruitment include Facebook, Twitter, and Instagram. Approval to conduct the study will be gained from all organizations and social media groups prior to recruitment. Participants will be provided a survey link through a recruitment flyer (see Appendix A) which will be attached to all e-mails and group postings. E-mail scripts (see Appendix B) and social media scripts (see Appendix C) will be used in order to recruit participants. Appendix C contains two separate scripts due to character limits of various social media websites. Other recruitment procedures will include attending virtual support groups of various organizations and reading the recruitment script at the conclusion of the group (See Appendix D). Anyone who expresses interest in participating will be directed to either the groups virtual chat box or e-mailed by the group host. The host will be provided the recruitment e-mail and flyer to send interested participants. Informed consent will be required to ensure the 
participants know their responses will be recorded and analyzed. After informed consent is approved by the participant they will be able to continue to the survey (see Appendix E)

Study Design. The design is a descriptive mixed-methods design as it will involve quantitative and qualitative components (Shorten \& Smith, 2017). The quantitative component will consist of close-ended questions and a Likert rating scale, while the qualitative aspect will be open-ended questions. A mixed methods approach to research was chosen as it allows for a more comprehensive utilization of data (Wisdom \& Cresswell, 2013).

The primary data source will include a survey as this will be distributed and managed directly by the student researcher (University of Minnesota, 2020). Secondary data sources will include preexisting literature and resources as these will reveal what gaps currently exist and can guide data collection. Purposive sampling will initially be used as the student researcher needs to ensure the study includes only participants that fit the inclusion criteria. The survey will start with the informed consent and then will redirect the participants to answer if they are an individual with a PND or a partner and what diagnosis they/their partner have. If individuals or their partners meet the inclusion criteria they will be redirected to continue to the survey. The survey will contain questions about demographics, current relationships, intimacy, perceptions of the effects of their/their partners diagnoses, and suggestions for future programming. The survey will be administered and collated through a Survey Monkey ${ }^{\mathrm{TM}}$ survey on a password-protected account on the student researcher's password-protected computer. Data will be analyzed utilizing Braun \& Clark thematic analysis outlined by Braun \& Clark (2006). Open-ended responses will be organized and coded by the student researcher using Dedoose coding software. Once coded, the data will then be analyzed by the student researcher and co-investigator separately in order to identify initial themes. The initial identified themes will then be discussed among the student 
investigator and co-investigator to combine themes. This method was chosen as discussion of codes and themes between multiple researchers increases rigor in qualitative research (Barbour, 2001).

\section{Program Development}

Data gained during the first portion of the capstone experience will be used to inform the creation of a detailed program proposal in the form of a workbook.

Development and Implementation Process. The themes identified from surveys will be integrated into a preliminary program design. Due to the limited time of the capstone experience, it is not expected that a full program will be developed. However, the OT student researcher will begin creating a resource that integrates the identified themes. It will be important that the resource takes into consideration the progressive nature of these disorders and offers interventions that are graded up and down to account for varying levels of function.

\section{Education and Advocacy}

Education for an OT audience on their role in addressing sexuality is imperative to increase confidence and awareness of how to target this important area of occupation. During the capstone experience, lessons focused on sex and intimacy will be created for "Clinical Application in Geriatrics" and "OT Methods 1: Assistive Technology" courses at the University of St. Augustine for Health Sciences (See Appendix F and G, respectively). Both lessons will include the importance of addressing sex and intimacy, OT's role, and model application as it applies to the class. The geriatrics presentation will focus on challenges (precautions and contraindications) and supports (positioning, preparatory methods, and task and tool adaptations) related to common geriatric diagnoses. The assistive technology presentation will focus on devices, positioning aids, and durable medical equipment that can be used to support 
occupational performance in sexual occupations.

\section{Methods Conclusion}

This capstone aims to develop a program addressing intimate occupations for individuals with PND based on their perceived barriers and concerns and recommendations to programming.. The project will include a mixed methods study to gain a more comprehensive understanding of the lived experience of individuals with PND in order to create a program to fit their identified needs. This project places the person with PND and partners in the role of expert on their conditions and seeks to explore their recommendations to influence effective programming. Furthermore, this capstone will enhance the role of occupational therapy in addressing sexual occupations. 


\section{Chapter 4: Results and Analysis}

Both individuals with PND and their partners were included in this study; however, due to time constraints and the volume of qualitative responses, results and analysis will only focus on the responses of individuals with PND. This study contained both a quantitative portion as well as a qualitative thematic analysis. This study aimed to answer the research question: What are the perceived impacts, barriers, and supports of PND on intimacy and sexual activity in individuals with PND and their partners?

\section{Participant Characteristics}

A total of 64 people with PND $(\mathrm{N}=64)$ participated in this study. Of these 64 participants, 26 had PD, 14 had MS, 11 had HD, and 13 had ALS. Demographic information was collected (see Table 1) as well as information regarding sexual orientation and their relationships (see Table 2). Participants were in a relationship for an average of 16.99 years. For the remainder of the results participants will be referred to by the number in which they took the survey in order to maintain confidentiality.

\section{Table 1}

Demographic Information

\begin{tabular}{|c|c|}
\hline Diagnosis & Number of Participants \\
\hline Parkinson's Disorder (PD) & 26 \\
\hline Multiple Sclerosis (MS) & 14 \\
\hline Huntington's Disease (HD) & 11 \\
\hline Amyotrophic Lateral Sclerosis (ALS) & 13 \\
\hline Age & Number of Participants \\
\hline $18-29$ & 4 \\
\hline $30-39$ & 12 \\
\hline $40-49$ & 14 \\
\hline $50-59$ & 18 \\
\hline $60-69$ & 13 \\
\hline $70-79$ & 3 \\
\hline
\end{tabular}




\begin{tabular}{|c|c|}
\hline Gender & Number of Participants \\
\hline Female & 46 \\
\hline Male & 18 \\
\hline Race & Number of Participants \\
\hline Asian/Asian American & 1 \\
\hline Black/African & 1 \\
\hline Hispanic/Latinx & 7 \\
\hline Native American & 2 \\
\hline Pacific Islander & 0 \\
\hline White & 55 \\
\hline Prefer not to answer & 1 \\
\hline Other (please specify) & 1 ("Italian") \\
\hline Religion & Number of Participants \\
\hline Buddhist & 1 \\
\hline Catholic & 18 \\
\hline Christian & 21 \\
\hline Jewish & 3 \\
\hline Hindu & 0 \\
\hline Muslim & 0 \\
\hline Native American & 1 \\
\hline Protestant & 7 \\
\hline Inter/Non-denominational & 3 \\
\hline No religion & 10 \\
\hline Other (please specify) & 1 ("LDS"), 1 ("Baptist") \\
\hline
\end{tabular}

\section{Table 2}

\section{Relationship Information}

\begin{tabular}{|c|c|}
\hline Sexual Orientation & Number of Participants \\
\hline Straight/Heterosexual & 57 \\
\hline Gay or Lesbian & 2 \\
\hline Bisexual & 5 \\
\hline Relationsip Status & Number of Participants \\
\hline Partnered & 58 \\
\hline Single and interested in partnership & 5 \\
\hline Single and not interested in partnership & 1 \\
\hline Sexual Status & Number of Participants \\
\hline Sexually active & 50 \\
\hline Not sexually active and interested in sexual relationships & 9 \\
\hline Not sexually active and interested in sexual relationships & 5 \\
\hline
\end{tabular}




\section{Quantitative Results}

\section{Satisfaction}

The participant survey included self-report questions about participant satisfaction in sexual activity and intimacy. Of the 64 participants, five reported not being in a relationship. Figure 1 illustrates participant rating in satisfaction with their intimate relationship. Thirty-six participants (56\%) reported they were "very satisfied" or "satisfied" in their intimate relationships. Fourteen participants rated their satisfaction as "neutral" and nine (14\%) reported being either "dissatisfied" or "very dissatisfied". Results for satisfaction in sexual activity are depicted in Figure 2. When rating sexual activity, more participants $(\mathrm{N}=8,12.5 \%)$ reported not being sexually active. Thirty-four participants (53\%) reported being "very satisfied" or “satisfied". While eight participants (12.5\%) reported being either "dissatisfied" or "satisfied".

\section{Figure 1}

Participants Reported Satisfaction in Intimate Relationships

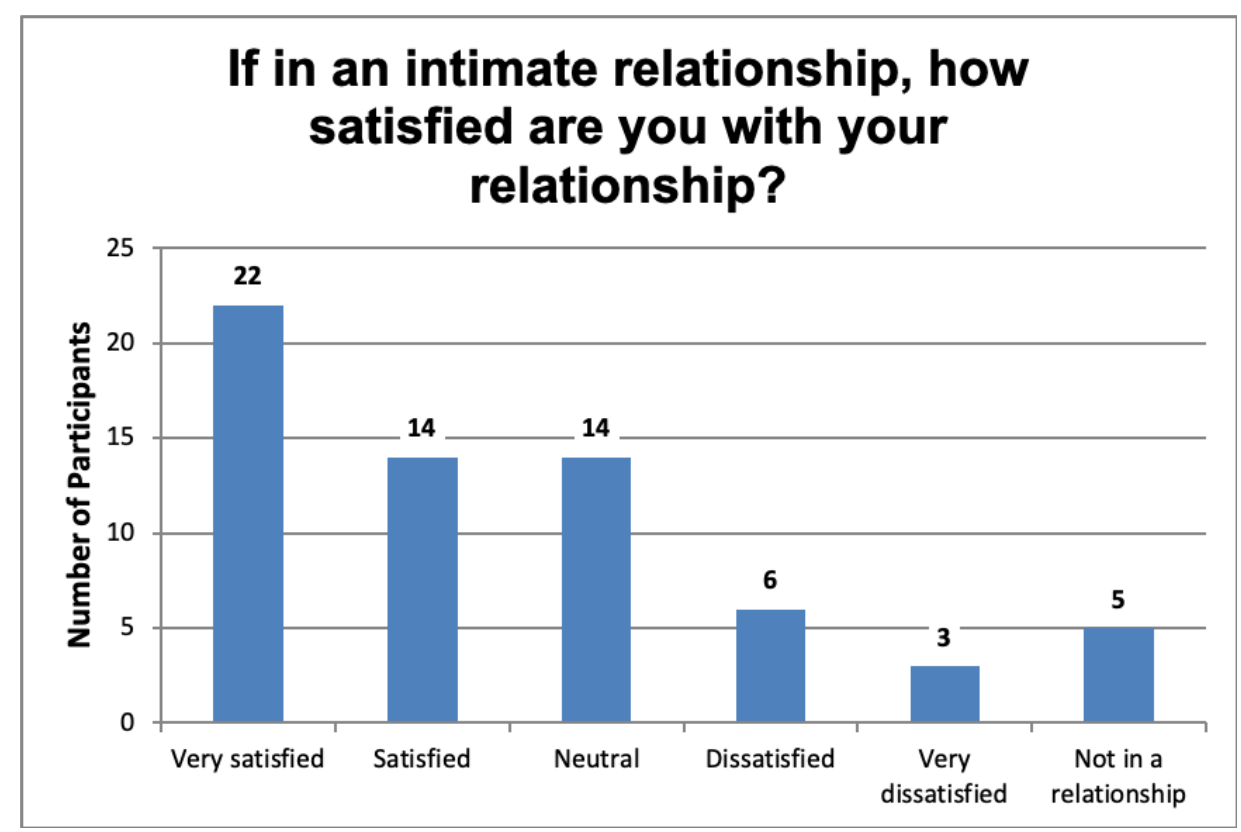




\section{Figure 2}

Participants Reported Satisfaction in Sexual Relationships

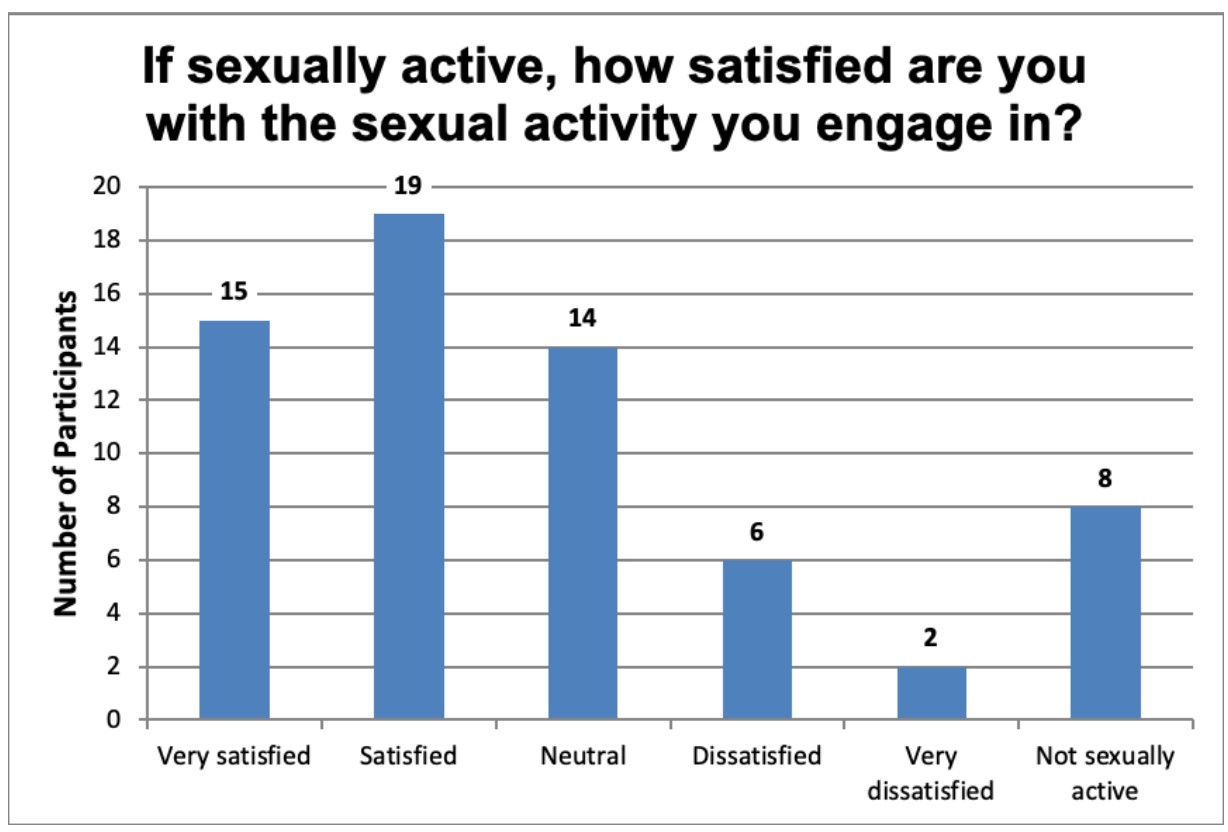

\section{Effect of Diagnosis}

Participants were asked about their perceived effects of their diagnosis on their intimate and sexual relationships. Figure 3 and 4 show the participants reported effect on their intimate and sexual relationships, respectively. Twenty-five percent $(\mathrm{N}=16)$ of participants reported not feeling that their diagnosis effected their sexual relationships. Four participants reported their diagnosis had a positive effect on their sexual relationship, while 27 reported only negative effects. Seventeen participants reported both positive and negative effects on their sexual relationships. As for the intimate aspect of their relationships, 19 participants reported no effects of their diagnosis. One participant reported only positive effects, while 25 reported only negative effects. Last, 19 participants reported their intimate relationship was both positively and negatively affected. 


\section{Figure 3}

Participants Reported Effects of Diagnosis on Intimate Relationships

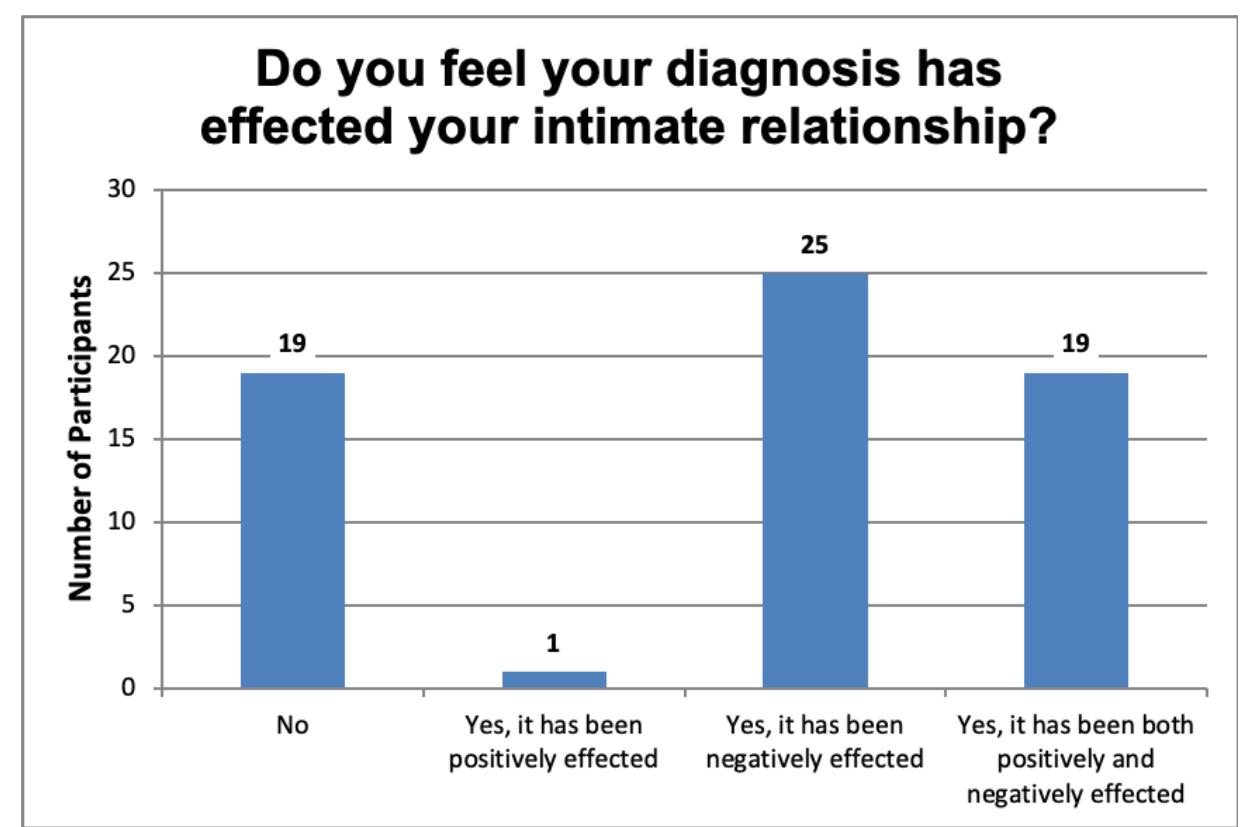

Figure 4

Participants Reported Effects of Diagnosis on Sexual Relationships

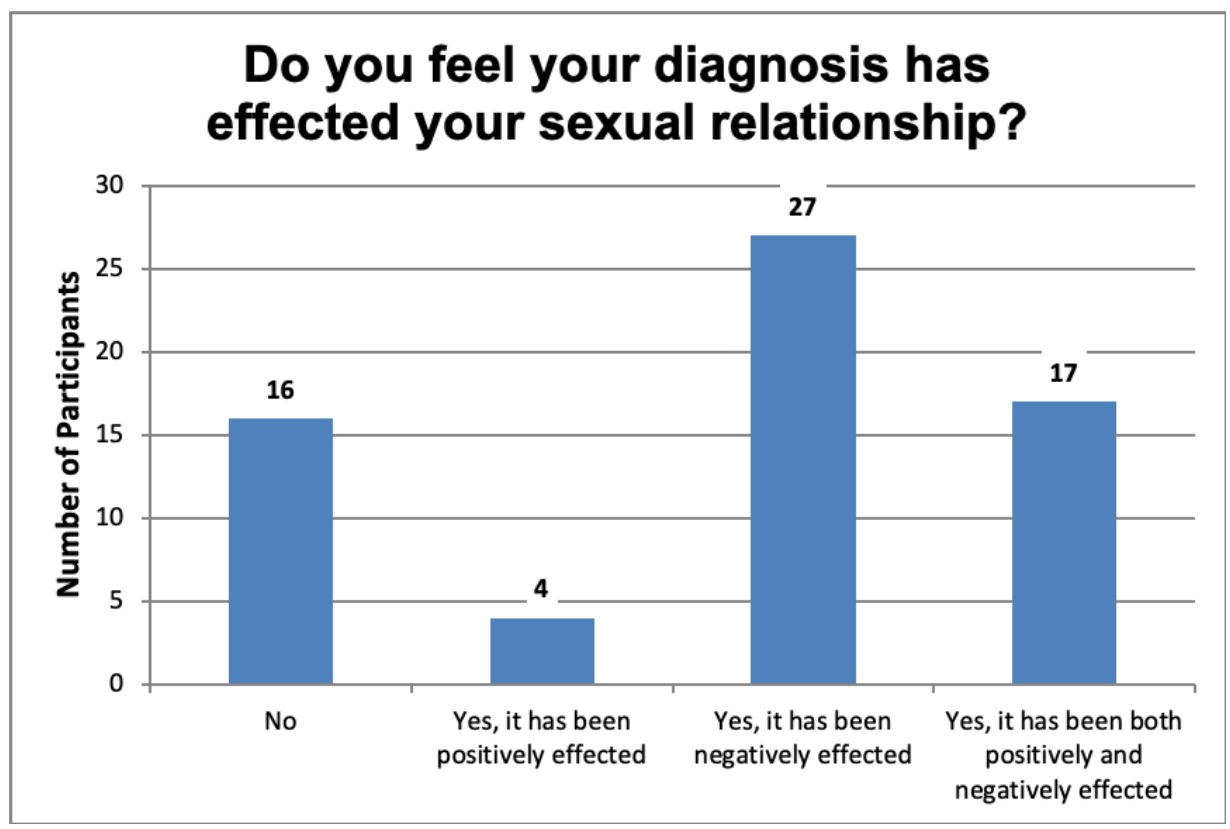




\section{Current Sexual Health Care and Comfort}

Participants were asked if they were currently receiving treatment from healthcare professionals regarding their relationship and if they feel comfortable seeking help. Out of 64 participants, $55(85.9 \%)$ reported they had received no treatment covering their relationships. The participants who had answered they have received treatment were then asked to identify what healthcare professionals have worked with them. The participants reported having been treated by counselors, therapists, medical doctors, neurologist, social workers, psychologists regarding their relationships. Seventy-five percent $(\mathrm{N}=48)$ of participants reported being comfortable with discussing issues regarding their relationships with healthcare professionals, while the remaining $25 \%(\mathrm{~N}=16)$ did not feel comfortable. Fifteen out of the 16 participants that reported discomfort receiving treatment had also reported receiving no medical treatment from healthcare professionals.

\section{Figure 5}

Participants Reported Sexual Healthcare Treatment

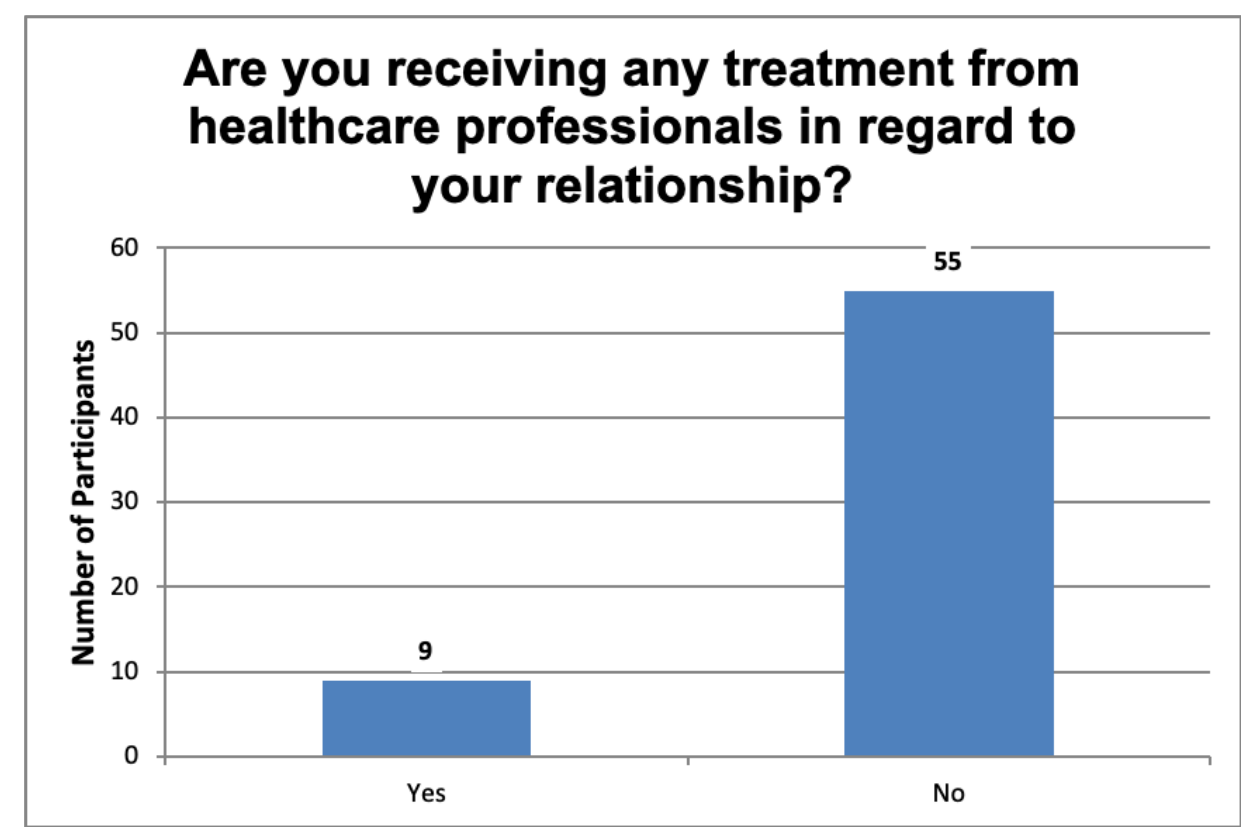




\section{Figure 6}

Participants Reported Comfort Seeking Treatment

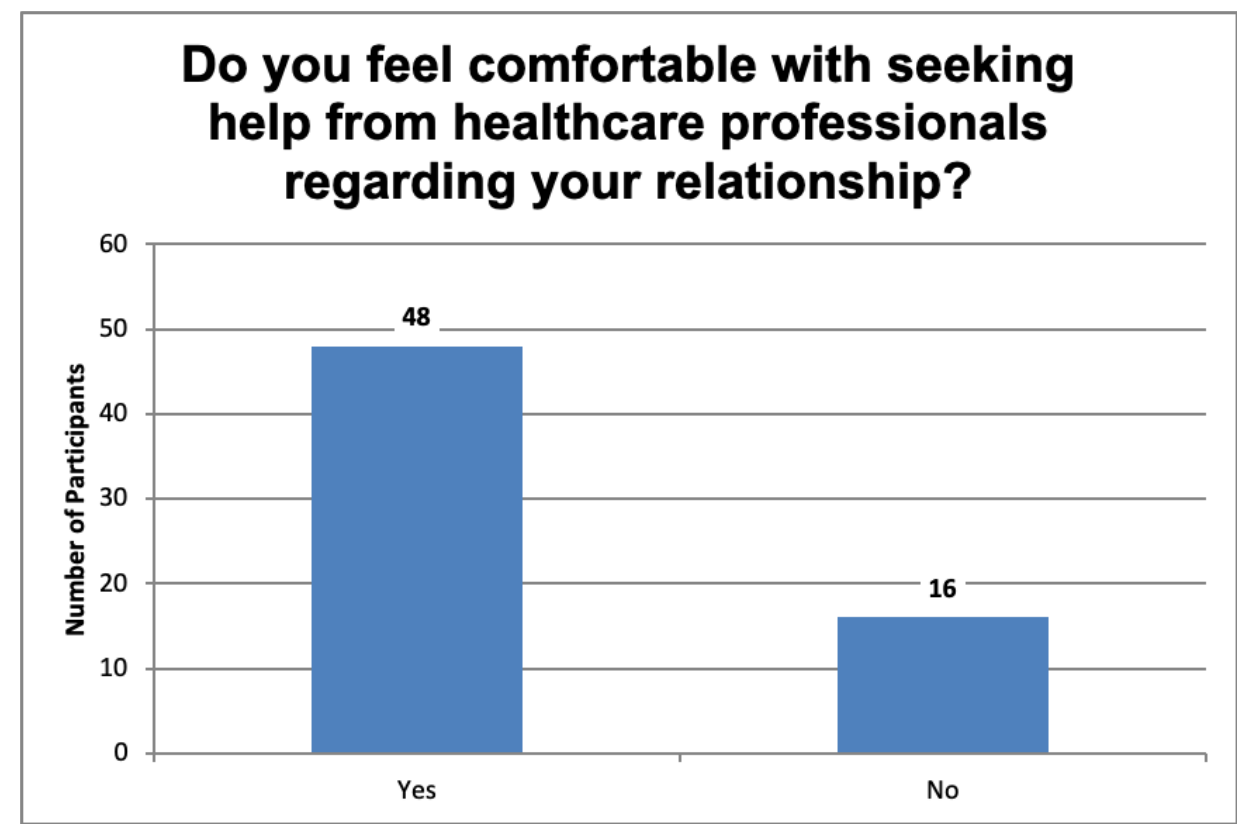

\section{Thematic Analysis}

The Braun \& Clark (2006) approach to thematic analysis was used to analyze qualitative data collected during this study. This method contains the following six phases to identify themes; 1) getting familiar with the data, 2) generating initial codes, 3) searching for themes, 4) reviewing the themes, 5) generating definitions and names for themes, and 6) producing a report of the analysis (Braun \& Clark, 2006).

Phase 1 involved the student researcher reading and becoming familiar with the data in order to form initial ideas before initiating coding. Phase 2 involved the student researcher systematically coding data by highlighting excerpts and tagging main features. At the conclusion of phase 2, a total of 171 codes were collated across the entire data set. Before initiating phase 3 the OT student researcher consulted with doctoral faculty and individuals experienced in qualitative research to become more familiar with the process of collating codes into themes. 
Phase 3 involved the OT student researcher and co-investigator analyzing codes and generating potential themes separately in order to increase rigor of the study (Barbour, 2001). Phase 4 included the student researcher and co-investigator reviewing their themes separately in relation to the entire data set to ensure they align. During phase 5, the student researcher and coinvestigator came together to discuss their separately generated themes and come to a consensus on final themes. The following themes were identified from survey data: physical symptoms impacting quality of sexual activity, relationship with emotions, connectedness, and actions that support engagement in sexual activity. Phase 6 involved selecting excerpts that represented themes well and answered the research question to produce the final report.

\section{Physical Symptoms Impacting Quality of Sexual Activity}

Participants felt that physical symptoms impacted their quality or ability to participate in sexual activity. Fifty-five participants described at least one physical barrier to participating in sexual activity and intimacy.

Sensorimotor. The most cited sensorimotor symptoms were pain $(26.5 \%, N=17)$, fatigue $(25 \%, \mathrm{~N}=16)$, and weakness/paralysis $(17 \%, \mathrm{~N}=11)$. Participants described the debilitating effects these symptoms can have on their activity. Participant 87 described, "The fatigue is crippling at some points...", while another participant (2) stated, “...unbearable pain, so NO intercourse". Other reported symptoms included dexterity, rigidity, cramps and spasms, and other diagnosis specific symptoms (i.e. tremors, dystonia, chorea, bradykinesia). The changing physical capabilities and progression of symptoms is inevitable due to the nature of these diagnoses and was reported as greatly impacting sexual activity and intimacy.

Erectile Dysfunction and Vaginal Dryness. Numerous participants reported erectile dysfunction and vaginal dryness as barriers to participating in sex. Participant 5 described, "I still 
have good sex drive but have trouble maintaining an erection". Though erectile dysfunction alone was reported in many participants, the secondary effects were also reported, "fear of impotence hitting my halfway along...I have to rush things before I lose erection" (Participant 65). Vaginal dryness was another physical barrier participant reported that caused pain. Participant 2 described, “...vaginal dryness that causes unbearable pain...”. The participants outlined how these symptoms can greatly impact their ability to participate or made them stop participating completely.

\section{Relationship with Emotions}

Another emerging theme was the impact emotions played in relationships and within themselves. Subthemes that were identifies were those who opened up, those who shut down, and the effect stress had on participants.

Open up. Some participants described a positive change in emotional connection and awareness. Participants reported the importance of opening up to their partner and "staying emotionally connected" (Participant 29). For example, participant 87 described the significance of checking in with each other, “...actually having a day to sit down and check in with each other either monthly, weekly, or after a flare up". Participant 2 described the importance of also processing the more difficult emotions as a means of improving understanding. They stated, “...be open with all the feelings. Even the ones that are the hardest to understand yourself".

Shut down. Some participants expressed emotions being impacted in a negative manner and described shutting down. Participant 69 described, 'I sometimes 'shut down' inside and don't know why and I am not as 'in' the relationship at times". The change in emotions within the relationship was also described by participant 84 . They said,

“Open conversations were super bad. Like depressing. No connection. No deep check ins. 
Just superficial "how are you today? How are you feeling" then a "good or bad" could end that. I wished he dug deeper but never did. And I was hurting too much to open up.. as it turns out so was he and he thought talking about it would make it worse because then we would feel sad and cry... but actually I wanted him too. I wanted to know his world was rocked like mine. That he's understood the severity of it all. That he was processing it. "Negative" emotions aren't bad, they're just hard but they're necessary for coping and grieving and moving forward.

This participants description outlines the need for processing of emotions no matter how negative in order to properly cope and grieve. Others expressed depression, anxiety, and apathy that were not present prior to diagnosis.

Stressors. This subtheme emerged as many participants discussed the role stress played within their relationships secondary to their disease, but also outside life stressors. Participants described stress related to a variety of disease related factors including limited mobility, fatigue, COVID-19, fear of the future, and mortality. Participant 70 explained the importance of, "being able to separate intimacy and sex from the stresses of everyday life and to not think about MS while in the bedroom". Numerous participants also expressed outside life stressors impacting their relationship. These external stressors included work, living arrangements, and personal and family life as barriers that impacted sexual activity. Participant 70 described, "it's hard to separate the stresses of life to enjoy the moment." Having stress is inevitable, but participants emphasized this as having an impact in their life. Many explained that they would benefit from stress management techniques as a means of coping with the stress of their disease as well as life in general.

\section{Connectedness}


Many participants described connection as an important factor that was impacted since their diagnosis. For some this was a supporting factor and for others with was a barrier. The subthemes that surfaced were connectedness as a replacement for sex, as an enhancement for sex, and varying partner roles.

Replacement for Sexual Relationship. The first subtheme was connection being a replacement for sex. Many participants reported the inability to continue having sex, but their connection fulfilling that particular need. Participant 2 illustrates this subtheme as they said:

"Facts being, sometimes, you accept things as they are and go forward, doing without some things in order to obtain other forms of closeness. Sexual expression can be in many other forms besides intercourse. The ability to relate to one's partner what desires one has and be willing to become creative. Even if it means satisfying your partners needs before and without satisfying your own. It is not their fault that the disease happens. Having a relationship that depends on sex is not a truly lasting concept. Sex is not love. Love does not mean sex. They are completely separate beings..."

As this participant describes, relationships do not need to rely on sex to keep that connection and love. Other participants reported no longer having a sex, but instead showing their love through intimate actions. Participant 39 said, “[partner] knows I'm in pain but he is always rubbing my hands and telling me he loves me". Participant 99 described a similar experience, "We kiss, hold hands, hug and express our love for each other a lot". Due to pain or decreased mobility many participants had ceased having sex. However, they were satisfied with maintaining closeness and love through more intimate connection as a replacement.

Enhancement for Sexual Relationship. Another theme that emerged was connectedness enhancing some participants sexual relationships. Many participants that reported continuing 
sexual activity also reported their connection as being a support in their sexual relationship.

Participant 74 described a support to engaging in sexual activity as, "the connection with my husband and closeness". Other participants described feelings, trust, love, connection, companionship, desire, and being in a loving relationship as sexual supports.

Partner's Role. The role a partner plays, whether supportive or not, was reported to be impacted in individuals with PND. Nineteen participants reported the role their partner played in their relationship as being a major support in their intimate and sexual relationships. Participant 58 stated, “my partners are all supportive and make me feel wanted and accepted. They see I'm still a sexual person despite my diagnosis". Other participants described their partner being understanding despite their challenges. For example, Participant 108 stated, "I have off times with Parkinson's. During these periods, I am not interested in sex. My husband is very understanding." Another participant (59) reaffirms this by saying, "my spouse is very understanding and willing to work with me as much as possible”. Last, some participants described their self-confidence being supported by their partners continued attraction. Participant 75 describes, “my husband still finds me as 'darn sexy'. While another participant (99) said, “...my husband tells me I am sexy even when I know I look like crap.” These participants illustrate that support and understanding from their partners have helped foster a stronger connection and self-concept.

On the contrary, some participants reported the impact their diagnosis has had on the role of their partner and the resultant negative feelings. Participant 55 described, "[her partner] says he is here to help but rarely does. [He] has done zero work in finding out how to be a helpful caregiver" and continued to say, "I feel the intimacy is starting to be replaced with resentment". Another participant described, "not feeling supported, not being in the mood, lack of open 
communication" (88) as a barrier to intimacy and sexuality within their relationship. Lack of communication, sharing, and decreased trust were also reported by participants as changing since their diagnosis. These participants illuminate the negative impacts that these diagnoses can have on connection and overall relationship quality.

\section{Supporting Actions}

A final theme that emerged was actions that individuals with PND took in order to support their sexual relationships. These included a range of both internal and external supports. The following were described as supports to engaging in sex and intimacy: empowered selfconcept, changing what sex looks like, and biopsychosocial changes.

Empowered Self-Concept. An important aspect that was impacted in participants was a feeling of empowerment. Individuals described that they are still a normal human being despite their diagnosis. Participant 94 said, “...this diagnosis doesn’t mean you are broken in any way.” Other participants described the importance of still being seen as a sexual being by saying, “...understand that it's not shameful to be horny" (16) and, "[partners] see I'm still a sexual being despite the diagnosis (58). Participant 100 described, "knowing I deserve to be loved" as a support for intimacy. These participants outline the importance of feeling empowered and a positive self-concept in supporting their intimate and sexual relationships.

Changing What the Sex Looks Like. Many participants reported that their diagnosis affected how they continue to engage in sex. As participant 58 described, "Due to the decline in my physical capabilities, we are limited in how we can physically pleasure each other. We find ways, however, to continue to have sexual relations." Some other aspects of sexual activity that participants reported changed were shifts in focus of sexual activity, physical adaptation, requiring planning, and increased need for communication. Responses describing varietal 
changes in sexual activity are reported in Table 3. Participants described changes in focus included less emphasis on penetration and more on intimate acts like hugging and holding hands. A need for planning or scheduling was described to ensure symptoms do not interfere as much as possible. Physical adaptations included changes in positioning and the use of assistive devices. Last, many participants expressed the importance of communication to support changing sexual capabilities. They mentioned humor and laughter as being an important aspect of communication that supports their relationships.

Table 3

Excerpts Describing Changes in Sexual Activity

\begin{tabular}{|c|c|}
\hline Change & Participant response \\
\hline \multirow[t]{2}{*}{ Shift in focus } & , "...other ways beside penetration to have an intimate relationship" (58) \\
\hline & $\begin{array}{l}\text { "hugging and sleeping next to each other" (2) } \\
\text { "...we kiss, hold hand, hug and express our love for each other" (99) }\end{array}$ \\
\hline \multirow[t]{3}{*}{ Planning } & "Planning ahead to ensure I have enough physical energy" (105) \\
\hline & $\begin{array}{l}\text { "We have to make sure we both are okay it's not spontaneous anymore" } \\
\text { (89) }\end{array}$ \\
\hline & "Planning, developing a schedule for both of us" (81) \\
\hline \multirow[t]{2}{*}{ Physical adaptation } & $\begin{array}{l}\text { "Adapting sex to suit your needs.. different sexual movements can help } \\
\text { conserve energy" (105) }\end{array}$ \\
\hline & $\begin{array}{l}\text { "Being able to adjust what is happening sexually if needed by physical } \\
\text { limitation" (69) }\end{array}$ \\
\hline \multirow[t]{3}{*}{ Communication } & $\begin{array}{l}\text { "Making sure that your partner is aware of your symptoms and knows } \\
\text { what the best way to help...open communication without judgement..." } \\
(87)\end{array}$ \\
\hline & $\begin{array}{l}\text { "Communication for sure. I am very open with my bf [boyfriend] about } \\
\text { my feelings, wants and needs." (100) }\end{array}$ \\
\hline & $\begin{array}{l}\text { "It is amazing how things can get so frustrating and cause me to start } \\
\text { shutting down, and he will joke about something and get me laughing } \\
\text { and we are able to finish up (69) }\end{array}$ \\
\hline
\end{tabular}

Biopsychosocial Supports. Along with communication changes within their relationships, participants reported seeking peer support as having an important impact. 
Participants described that it helped to, “...listen to others in the same situation” (78) while others stated, "feeling supported by their communities" as making a meaningful impact. Another social support was quality time with their partners. Partner 84 stated, "Quality time and engagement!!!! Really taking time to learn about one another, be a team with dual decision making, and enjoy each other...”. Participants also emphasized this theme in saying the importance of, "more quality time together and allowing us a chance to talk in depth" (84) and "make time to spend together alone" (78). External social supports were clearly important to participants and had a positive impact on their ability to engage in sexual and intimate activities.

Another support reported by many were the benefits of orgasms, participating in sex, and medications. Participant 65 stated, “orgasm encourages me to keep living” while another participant (13) said, "since my ALS diagnoses it feels like my whole body benefits from having an orgasm". These excerpts clearly represent the importance of sexual activity regardless of physical status and how meaningful and beneficial it can be. Others explained that they feel sex has a positive effect on their mood and their physical well-being as it stimulates muscles they may not use otherwise. Medications were also very helpful to some participants that experienced erectile dysfunction, vaginal dryness, or had on-off times. Performance enhancers were cited as helpful to many participants to last longer and reduce pain. Medication timing was also discussed as this can affect energy level and movement quality. 


\section{Chapter 5: Discussion and Conclusion}

\section{Discussion}

Previous research has shown that individuals with PND can face many physical, psychological, and social challenges (Mackett, 2016). Furthermore, the progressive nature of PND usually necessitates an increased need for care. Oftentimes, partners take on a caregiving role which can result in frustration and resentments and put strain on the relationship (Vatter et al., 2018). These challenges can lead to negative psychological changes in both the individual and their partners (Mosley et al., 2017). However, these relationships have been reported to be strengthened with open communication, self-disclosure, and empathetic response skills (KardanSouraki et al., 2015). The themes that emerged throughout this study align with past research studies, but also add to the body of literature in numerous ways. First, it contains a qualitative component that helps to better understand the lived experience of individuals with PND. Second, it describes how these functional and relational changes directly and indirectly impact sexual and intimate relationships. Last, this study included questions regarding advice and suggestions for future programming that can support their specific needs. Including these elements was vital to understanding where information is lacking for these individuals and taking necessary steps toward improvement in somatic, emotional, and social domains impacting sex and intimacy.

Due to the change in physical ability many participants reported changes in the way they participate in sexual activity. Their descriptions demonstrate a need for flexibility and willingness to change how they typically perform sexually in order to successfully continue participating. This indicated the need for support in these areas for individuals with PND who struggle to participate in sexual activity, but express interest in continuing. Due to the progressive nature of these disorders, modification is often needed rather than remediation. 
Though this is the case, there are suggestions that can be made to alleviate certain symptoms that were identified as barriers. For example, pain management and energy conservation strategies can help improve participation in intimate and sexual activities. Another support many identified was the use of toys and the importance of breaking down the negative stigma of using assistive devices during sex. It is important to help individuals with PND that may have stigma toward assistive device use consider the positive impact toys can have on a relationship.

Another theme that emerged was the participants relationship with their own emotions and life circumstances. Participants expressed either opening up to their emotions or shutting down. It is important to be aware of the psychological effects PND can have on these individuals in order to provide them with proper supports. A number of participants also expressed both stress from their disease as well as from outside life stressors. It is important that all aspects of a person be considered and things like stress management techniques can be introduced as a means of support. Stress was described as sometimes exacerbating participants symptoms so overall stress reduction should be a priority with individuals with PND.

Those with supportive partners who felt a deeper connection were generally satisfied regardless of ability to engage in sexual activity. In some participants they expressed their diagnosis actually bringing them closer. This illustrates the importance of communication and connection within relationships for these individuals. While many reported having supportive partners, there were other participants that outlined the challenges of having an unsupportive partner. Those who felt connection being lost or a lack of support expressed feelings of resentment and depression. Whether partners were supportive or not, this subtheme outlines the important role that the partner has in individuals with PND psychosocial well-being. Babaee and Ghahari (2016) describe the importance of open communication in strengthening intimate 
relationships. This displays the importance of considering the social contexts of individuals with PND in order to foster psychological growth and well-being. It is important to consider that some of these individuals may have been struggling in communication with their partner and felt a lack of support before their diagnosis. However, questions were specifically framed to prompt responses of impacts post-diagnosis.

The last theme that was derived from this research is what changes participants made in their relationships that worked at improving sex and intimacy. A variety of factors were listed such as positive mind set, quality time with partners, peer support, medications, and creative adaptations. This study placed the individual with PND at the forefront in order to gain knowledge about where they feel supported, limited, and impacted regarding their relationships. Gaining suggestions directly from individuals with PND is vital in providing supports that can aid this population with improving their participation in sex and intimacy. Therefore, this study highlights the importance of considering the perspectives of individuals with PND in order to create individualized and holistic programming.

\section{Envisioned Next Steps}

This study identified barriers in sexual and intimate relationships reported by individuals with PND. Due to the time constraints and quantity of responses to the survey, the data collected on partners has not yet been analyzed. This will be a vital next step in creating programming that takes the opinions of both individuals with PND and their partners into consideration. In order to decrease these barriers, the researcher plans to create a resource for individuals with PND and their partners catered to their identified needs. It is vital to continue to keep the opinions of the targeted population at the forefront during the creation of this resource. Therefore, focus groups will be held to gain feedback from individuals with PND and their partners in order to ensure the 
suggestions are suitable to fit these individual's needs. The resource will consistently be modified to incorporate participants suggestions. Once the research is summarized and resource design is finalized, a presentation will be created in order to share findings with key stakeholders. These stakeholders will include individuals with PND and their partners as well as healthcare professionals that specialize in working with the target population or sex and intimacy. This presentation will relay information found during the original research component of this project as well as outline what users will gain from the resource.

It is important that occupational therapists increase their role in addressing sex and intimacy with clients. Due to the holistic nature of the profession they are equipped with unique skills to address physical, emotional, and relational barriers in order to improve client's quality of life. Therefore, another future step is to advocate for OT's increased role in addressing this important occupation both within the profession and with other healthcare professionals.

\section{Implications for Occupational Therapy}

Individuals with PND that participated in this study cited numerous supports and barriers to engaging in sexual activity. Supports included opening up and communicating, connection with partner, positive mindset, and adapting sexual activity. Adaptations that participants mentioned as supports to participating in sexual activity included using assistive technology (i.e. sex toys), adaptive positioning, and incorporating sex into a schedule or planning ahead for sex. Barriers reported by participants included physical and psychological symptoms, stress, and unsupportive partners. This information can be used to inform OT interventions as practitioners can provide support in areas of communication and mindset reframing in patients who may be struggling in this area. Occupational therapy interventions related to improving communication between both partners can include working on assertive communication and empathetic listening 
skills. Further psychosocial interventions can include addressing maladaptive thoughts about sexual abilities using the cognitive behavioral frame of reference. Furthermore, occupational therapists can collaborate with clients to identify strategies to better manage their stress. Energy conservation is also essential in improving the sexual lives of the target population as fatigue was a barrier reported by many participants.

Though individuals with PND still have the desire to participate in sex and intimacy, they often do not get treated as a sexual being within the healthcare environment. The findings from this study support an increased role for OT practitioners in the domain of sexuality. Occupational therapists can facilitate meaningful participation in sexual occupations for these individuals by addressing: their unique physical barriers through positioning and adaptations, providing stress management strategies for both internal and external stressors, and facilitating positive communication between individuals with PND and their partners. It is important to note that occupational therapists cannot be expected to address all areas of concern with individuals with PND as their challenges can be very unique. However, this study supports the need for an interprofessional care team to address any barriers and get them participating as best they can with what function they have. This research reaffirms that sexual occupations should not go unaddressed as these can be beneficial not only to the individual patients well-being, but their partnership and social domains as well.

\section{Conclusions}

This study aimed to identify the perceived impacts, supports, and barriers of individuals with PND regarding sex and intimacy. This capstone adds to the literature as it provides insight into the lived experience of individuals with PND and their partners regarding sexual and intimate aspects of their relationships. This project supports increased involvement of 
occupational therapists in addressing sex and intimacy for individuals with PND and their

partners as they bring a unique contribution to the healthcare team. Further research examining specific interventions that are successful with this population is necessary in improving their care regarding sexual occupations. 


\section{References}

Aarsland, D., Marsh, L., \& Schrag, A. (2009). Neuropsychiatric symptoms in Parkinson's disease. Movement Disorders, 24(15), 2175-2186. https://doi.org/10.1002/mds.22589

Adam, F., De Sutter, P., Day, J., \& Grimm, E. (2020). A randomized study comparing videobased mindfulness-based cognitive therapy with video-based traditional cognitive behavioral therapy in a sample of women struggling to achieve orgasm. The Journal of Sexual Medicine, 17(2), 312-324. https://doi.org/10.1016/j.jsxm.2019.10.022

American Occupational Therapy Association [AOTA]. (2013). Sexuality and the role of occupational therapy. https://www.aota.org/About-OccupationalTherapy/Professionals/RDP/Sexuality.aspx

American Occupational Therapy Association [AOTA]. (2014). Occupational therapy practice framework: Domain and process. American Journal of Occupational Therapy, 68(Suppl. 1), S1-S48. http://doi.org/10.5014/ajot.2014.682006

Aubeeluck, A. V., Buchanan, H., \& Stupple, E. J. N. (2012). 'All the burden on all the carers': Exploring quality of life with family caregivers of Huntington's disease patients. Quality of Life Research, 21(8), 1425-1435. https://doi.org/10.1007/s11136-011-0062-x

Babaee, S. N., \& Ghahari, S. (2016). Effectiveness of communication skills training on intimacy and marital adjustment among married women. International Journal of Medical Research \& Health Sciences, 5(8), 375.

Bandura A. (1985) Model of causality in social learning theory. In: Mahoney M.J., Freeman A. (Eds) Cognition and Psychotherapy (pp. 81-99). Plenum Publishing Corporation. Barbour R. S. (2001). Checklists for improving rigour in qualitative research: a case of the tail 
wagging the dog?. BMJ (Clinical research ed.), 322(7294), 1115-1117.

https://doi.org/10.1136/bmj.322.7294.1115

Beier, M. L. (n.d.) Multiple sclerosis and mental health: 3 common challenges.

https://www.hopkinsmedicine.org/health/conditions-and-diseases/multiple-sclerosis$\underline{\mathrm{ms} / \text { multiple-sclerosis-and-mental-health-3-common-challenges }}$

Braun, V. and Clarke, V. (2006) Using thematic analysis in psychology. Qualitative Research in Psychology, 3 (2). pp. 77-101. ISSN 1478-0887

Bronner, G. (2011). Sexual problems in Parkinson's disease: The multidimensional nature of the problem and of the intervention. Journal of the Neurological Sciences, 310(1-2), 139143. https://doi.org/10.1016/j.jns.2011.05.050

Bronner, G., Royter, V., Korczyn, A. D., \& Giladi, N. (2004). Sexual dysfunction in Parkinson's disease. Journal of Sex \& Marital Therapy, 30(2), 95-105.

https://doi.org/10.1080/00926230490258893

Calabrò, R. S., Russo, M., Dattola, V., De Luca, R., Leo, A., Grisolaghi, J., Bramanti, P., \& Quattrini, F. (2018). Sexual function in young individuals with multiple sclerosis: Does disability matter? Journal of Neuroscience Nursing, 50(3), 161-166. https://doi.org/10.1097/JNN.0000000000000367

Chawla, N., \& Kafescioglu, N. (2012). Evidence-based couple therapy for chronic illnesses: Enriching the emotional quality of relationships with emotionally focused therapy. Journal of Family Psychotherapy, 23(1), 42-53. https://doi.org/10.1080/08975353.2012.654080

Clare, L., Teale, J. C., Toms, G., Kudlicka, A., Evans, I., Abrahams, S., Goldstein, L. H., Hindle, 
J. V., Ho, A. K., Jahanshahi, M., Langdon, D., Morris, R., Snowden, J. S., Davies, R., Markova, I., Busse, M., \& Thompson-Coon, J. (2019). Cognitive rehabilitation, selfmanagement, psychotherapeutic and caregiver support interventions in progressive neurodegenerative conditions: A scoping review. NeuroRehabilitation, 43(4), 443-471. https://doi.org/10.3233/NRE-172353

Daneshfar, F., Behboodi-Moghadam, Z., Khakbazan, Z., Nabavi, S. M., Nayeri, N. D., Ghasemzadeh, S., \& Montazeri, A. (2017). The influence of Ex-PLISSIT (extended permission, limited information, specific suggestions, intensive therapy) model on intimacy and sexuality of married women with multiple sclerosis. Sexuality and Disability, 35(4), 399-414. https://doi.org/10.1007/s11195-017-9482-z

Diamond, L. M., \& Huebner, D. M. (2012). Is good sex good for you? Rethinking sexuality and health. Social and Personality Psychology Compass, 6, 54-69. http://dx.doi.org/10.1111/j.1751-9004.2011.00408.x

Dobkin, R. D., Menza, M., \& Bienfait, K. L. (2008). CBT for the treatment of depression in Parkinson's disease: A promising nonpharmacological approach. Expert Review of Neurotherapeutics, 8(1), 27-35. https://doi.org/10.1586/14737175.8.1.27

Dolhun, R. (n.d.) Sexual and reproductive health with Parkinson's. https://www.michaeljfox.org/understanding-parkinsons/living-with-pd/topic.php?sexual$\underline{\text { health }}$

Dyer, K., \& das Nair, R. (2013). Why don't healthcare professionals talk about sex? A systematic review of recent qualitative studies conducted in the United Kingdom. The Journal of Sexual Medicine, 10(11), 2658-2670. https://doi.org/10.1111/j.1743$\underline{6109.2012 .02856 . x}$ 
Esmail, S., Darry, K., Walter, A., \& Knupp, H. (2010). Attitudes and perceptions towards disability and sexuality. Disability and Rehabilitation, 32(14), 1148-1155. https://doi.org/10.3109/09638280903419277

Forwell, S. J., Hugos, L., Copperman, L. F., \& Ghahari, S. (2014). Neurodegenerative diseases. In Radomski, M. V., \& Latham, C. A. (7th ed.), Occupational therapy for physical dysfunction (pp. 1078-1102). Baltimore, MD: Lippincott Williams and Wilkins.

Ghielen, I., Rutten, S., Boeschoten, R. E., Houniet-de Gier, M., van Wegen, E. E. H., van den Heuvel, O. A., \& Cuijpers, P. (2019). The effects of cognitive behavioral and mindfulness-based therapies on psychological distress in patients with multiple sclerosis, Parkinson's disease and Huntington's disease: Two meta-analyses. Journal of Psychosomatic Research, 122, 43-51. https://doi.org/10.1016/j.jpsychores.2019.05.001

Goldstein, L. H., Atkins, L., Landau, S., Brown, R., \& Leigh, P. N. (2006). Predictors of psychological distress in carers of people with amyotrophic lateral sclerosis: A longitudinal study. Psychological Medicine, 36(6), 865-875. https://doi.org/10.1017/S0033291706007124h

Haboubi, N. H. J., \& Lincoln, N. (2003). Views of health professionals on discussing sexual issues with patients. Disability and Rehabilitation, 25(6), 291-296. https://doi.org/10.1080/0963828021000031188

Hattjar, B. (2017). Addressing sexual activity: A structured method for assisting clients with intimacy. OT Practice, 22(19), 8-10, 12.

Hees, P.J., Plas, A.A., Ek, G.F., Putter, H., Oudsten, B.D., Ouden, M.E., \& Elzevier, H.W. (2017). Discussing sexuality with patients with Parkinson's disease: A survey among Dutch neurologists. Journal of Neural Transmission. 124(3), 361-368. 
https://doi.org/10.1007/s00702-016-1655-x

"Intimacy". (2019). https://www.goodtherapy.org/blog/psychpedia/intimacy

Jacobs, H., Vieregge, A., \& Vieregge, V. (2000). Sexuality in young patients with Parkinson's disease: A population based comparison with healthy controls. Journal of Neurology, Neurosurgery \& Psychiatry, 69(4), 550-552. https://doi.org/10.1136/jnnp.69.4.550

Kardan-Souraki, M., Hamzehgardeshi, Z., Asadpour, I., Mohammadpour, R. A., \& Khani, S. (2015). A review of marital intimacy-enhancing interventions among married individuals. Global Journal of Health Science, 8(8), 74. https://doi.org/10.5539/gjhs.v8n8p74

Levenson, R. W., Sturm, V. E., \& Haase, C. M. (2014). Emotional and behavioral symptoms in neurodegenerative disease: A model for studying the neural bases of psychopathology. Annual Review of Clinical Psychology, 10(1), 581-606. https://doi.org/10.1146/annurevclinpsy-032813-153653

Lichtenberg, P. A. (2014). Sexuality and physical intimacy in long-term care. Occupational Therapy In Health Care, 28(1), 42-50. https://doi.org/10.3109/07380577.2013.865858

Mackett, A. (2016). Parkinson's \& intimate relationships: A neglected area? https://parkinsonsacademy.co/2016/11/29/intimate-relationships/

Marck, C. H., Jelinek, P. L., Weiland, T. J., Hocking, J. S., De Livera, A. M., Taylor, K. L., Neate, S. L., Pereira, N. G., \& Jelinek, G. A. (2016). Sexual function in multiple sclerosis and associations with demographic, disease and lifestyle characteristics: An international cross-sectional study. BMC Neurology, 16(1). https://doi.org/10.1186/s12883-016-0735-8

Martinez-Martin, P., Rodriguez-Blazquez, C., \& Forjaz, M. J. (2012). Quality of life and burden in caregivers for patients with Parkinson's disease: Concepts, assessment and related factors. Expert Review of Pharmacoeconomics \& Outcomes Research, 12(2), 221-230. 
https://doi.org/10.1586/erp.11.106

Mayers, K. S., \& Heller, J. A. (2003). Sexuality and the late stage Huntington's disease patient. Sexuality and Disability, 21(2), 91-105. https://doi.org/10.1023/A:1025443300040

Mayo Clinic. (2020). Neuromuscular disease group. https://www.mayoclinic.org/departmentscenters/neuromuscular-disease-group/overview/ovc-20443670

McCabe, M. P., Firth, L., \& O’Connor, E. (2009). A comparison of mood and quality of life among people with progressive neurological illnesses and their caregivers. Journal of Clinical Psychology in Medical Settings, 16(4), 355-362. https://doi.org/10.1007/s10880009-9168-5

McGrath, M., \& Lynch, E. (2014). Occupational therapists' perspectives on addressing sexual concerns of older adults in the context of rehabilitation. Disability and Rehabilitation, 36(8), 651-657. https://doi.org/10.3109/09638288.2013.805823

McGrath, M., \& Sakellariou, D. (2015). Why has so little progress been made in the practice of occupational therapy in relation to sexuality? American Journal of Occupational Therapy, 70(1), 7001360010p1. https://doi.org/10.5014/ajot.2016.017707

McGrath, M., \& Sakellariou, D. (2016). The issue is: Why has so little progress been made in the practice of occupational therapy in relation to sexuality? The American Journal of Occupational Therapy, 70, 1-5. https://doi.org/10.5014/ajot.2016.017707

Mosley, P. E., Moodie, R., \& Dissanayaka, N. (2017). Caregiver burden in Parkinson disease: A critical review of recent literature. Journal of Geriatric Psychiatry and Neurology, 30(5), 235-252. https://doi.org/10.1177/0891988717720302

National Multiple Sclerosis Society. (n.d.). Sexual problems. https://www.nationalmssociety.org/Symptoms-Diagnosis/MS-Symptoms/Sexual- 


\section{Dysfunction}

Oh, H. \& Schepp, K.G. (2013). Wives becoming caregivers: The lived experiences of wives caring for amyotrophic lateral sclerosis patients. Journal of Hospice and Palliative Nursing. 2013;15:244-50.

O’Connor, S. R., Connaghan, J., Maguire, R., Kotronoulas, G., Flannagan, C., Jain, S., Brady, N., \& McCaughan, E. (2019). Healthcare professional perceived barriers and facilitators to discussing sexual wellbeing with patients after diagnosis of chronic illness: A mixedmethods evidence synthesis. Patient Education and Counseling, 102(5), 850-863. https://doi.org/10.1016/j.pec.2018.12.015

O’Connor, E. J., \& McCabe, M. P. (2011). Predictors of quality of life in carers for people with a progressive neurological illness: A longitudinal study. Quality of Life Research, 20(5), 703-711. https://doi.org/10.1007/s11136-010-9804-4

Oyebode, J. R., Smith, H.-J., \& Morrison, K. (2013). The personal experience of partners of individuals with motor neuron disease. Amyotrophic Lateral Sclerosis and Frontotemporal Degeneration, 14(1), 39-43. https://doi.org/10.3109/17482968.2012.719236

Pieters, R., Kedde, H., \& Bender, J. (2018). Training rehabilitation teams in sexual health care: A description and evaluation of a multidisciplinary intervention. Disability and Rehabilitation, 40(6), 732-739. https://doi.org/10.1080/09638288.2016.1271026

Poletti, B., Carelli, L., Solca, F., Pezzati, R., Faini, A., Ticozzi, N., Mitsumoto, H., \& Silani, V. (2019). Sexuality and intimacy in ALS: Systematic literature review and future perspectives. Journal of Neurology, Neurosurgery \& Psychiatry, 90(6), 712-719. https://doi.org/10.1136/jnnp-2018-319684 
Rees, P. M., Fowler, C. J., \& Maas, C. P. (2007). Sexual function in men and women with neurological disorders. The Lancet, 369(9560), 512-525. https://doi.org/10.1016/S01406736(07)60238-4

Rose, N., \& Hughes, C. (2018). Addressing sex in occupational therapy: A coconstructed autoethnography. American Journal of Occupational Therapy, 72(3), 7203205070p1. https://doi.org/10.5014/ajot.2018.026005

Schkade, J. K., \& Schultz, S. (1992). Occupational adaptation: Toward a holistic approach for contemporary practice, part 1. American Journal of Occupational Therapy, 46(9), 829837. https://doi.org/10.5014/ajot.46.9.829

Secker, D. L. \&. Brown, R. G. (2005). Cognitive behavioural therapy (CBT) for carers of patients with Parkinson's disease: A preliminary randomized controlled trial. Journal of Neurology, Neurosurgery \& Psychiatry, 76(4), 491-497. https://doi.org/10.1136/jnnp.2004.042291

Shorten, A., \& Smith, J. (2017). Mixed methods research: Expanding the evidence base. Evidence Based Nursing, 20(3), 74-75. https://doi.org/10.1136/eb-2017-102699

Solet, J. M. (2014). Optimizing personal and social adaptation. In occupational therapy for physical dysfunction (7th ed.) Baltimore, MD: Lippincott Williams and Wilkins.

Taylor, B. (2011). The impact of assistive equipment on intimacy and sexual expression. British Journal of Occupational Therapy, 74(9), 435-442. $\underline{\text { https://doi.org/10.4276/030802211X13153015305637 }}$

Taylor, R. R. (2008). The intentional relationship: Occupational therapy and use of self. F.A. Davis Co.

Taylor, B., \& Davis, S. (2006). Using the Extended PLISSIT model to address sexual healthcare 
needs. Nursing Standard, 21(11), 35-40.

https://doi.org/10.7748/ns2006.11.21.11.35.c6382

The Institute for Sex, Intimacy and Occupational Therapy. (2020). Mission.

https://www.sexintimacyot.com/pages/mission

The Institute for Sex, Intimacy and Occupational Therapy. (n.d.). Lesson 2: Sexuality, Intimacy, \& Occupational Therapy: Why We Care, and How We Do It. In Sexuality and Intimacy Throughout Lifespan : Level 1 Sex \& Intimacy Specialist.

https://www.sexintimacyot.com/products/sexuality-and-intimacy-throughout-lifespanlevel-1-sex-intimacy-specialist-1-hour-course/categories/1389641/posts/5331303

University of Minnesota. (2020). Data Sources. https://cyfar.org/data-sources

Vatter, S., McDonald, K. R., Stanmore, E., Clare, L., McCormick, S. A., \& Leroi, I. (2018). A qualitative study of female caregiving spouses' experiences of intimate relationships as cognition declines in Parkinson's disease. Age and Ageing, 47(4), 604-

610. https://doi.org/10.1093/ageing/afy049

Wasner, M., Bold, U., Vollmer, T. C., \& Borasio, G. D. (2004). Sexuality in patients with amyotrophic lateral sclerosis and their partners. Journal of Neurology, 251(4), 445-448. https://doi.org/10.1007/s00415-004-0351-1

Wisdom, J. \& Creswell, J. (2013). Mixed Methods: Integrating quantitative and qualitative data collection and analysis while studying patient-centered medical home models. Agency for Healthcare Research and Quality. https://pcmh.ahrq.gov/page/mixed-methodsintegrating-quantitative-and-qualitative-data-collection-and-analysis-while

World Parkinson's Coalition. (2017). Personal intimacy and sexuality in Parkinson's disease. https://www.worldpdcongress.org/home/2017/8/30/tej4amylqqchid93kjhydevlltcn0v 
Appendix A

Recruitment Flyer

\section{Recruiting Participants for Survey, I want to hear from you!}

I am an occupational therapy student examining the impacts of progressive neurodegenerative disorders (PND) on intimacy and sexual activity in individuals with PND and their partners.

Participants will be asked to participate in

- An online survey

- Time commitment should be about 15-25 minutes

Who?

- Individuals with the following diagnoses:

- Parkinson's Disease,

- Multiple Sclerosis,

- Huntington's Disease,

- Amyotrophic Lateral Sclerosis (ALS)

- Partners of those with the above diagnoses

- Adults 18 years or older

If you're eligible and interested in participating, The survey can be found at the following link or by scanning the QR code:

https://www.surveymonkey.com/r/OTintimacy
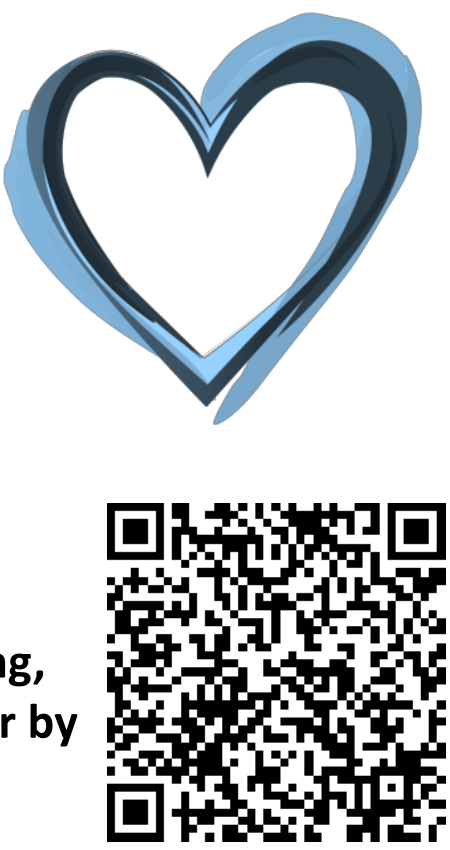

IRB \#0403-020

THIS PROJECT HAS BEEN REVIEWED BY THE UNIVERSITY OF ST. AUGUSTINE FOR HEALTH SCIENCES INSTITUTIONAL REVIEW BOARD FOR THE PROTECTION OF HUMAN SUBJECTS. 


\section{Appendix B}

Hello,

\section{E-mail Script}

My name is Lindsay Richards and I am an occupational therapy doctorate student at the University of St. Augustine at the San Marcos, CA campus. I am currently working on my OTD capstone project examining the impact of progressive neuromuscular disorders (PND) on intimacy in individuals with PND and their partners. In doing research, I found a lack of research examining the lived experience and perception of the impacts of individuals with PND and their partners.

Inclusion criteria for this study include adults over 18 years of age with Parkinson's disorder, Multiple Sclerosis, Huntington's disease, and Amyotrophic Lateral Sclerosis and their partners. The survey should take no longer than 25 minutes.

If you are interested in participating, the survey can be found at the following link: https://www.surveymonkey.com/r/OTintimacy

If you know anyone who meets criteria for inclusion and would be interested in taking the survey, I would greatly appreciate if you could forward them my information!

If you have any questions, please contact me at:

Thank you for your time and I appreciate your interest in participation in this survey.

\section{Lindsay Richards}

University of St. Augustine for Health Sciences, San Marcos

IRB \#0403-020

THIS PROJECT HAS BEEN REVIEWED BY THE UNIVERSITY OF ST. AUGUSTINE FOR HEALTH SCIENCES INSTITUTIONAL REVIEW BOARD FOR THE PROTECTION OF HUMAN SUBJECTS.

IF YOU HAVE QUESTIONS OR CONCERNS, PLEASE CONTACT THE

INSTITUTIONAL IRB CHAIR, DR. ELIZABETH ARDOLINO,

EMAIL: EARDOLINO@,USA.EDU, PHONE: 737-202-3343. 


\section{Appendix C}

\section{Social Media Scripts}

Hello everyone,

My name is Lindsay Richards and I am a doctoral student completing a research study on the impact of progressive neuromuscular disorders (PND) on intimacy in individuals with PND and their partners. The survey will contain both open- and close-ended questions about relationships as well as what you would look for in a program addressing these topics. My hope is to further understand the impacts of these diagnosis on your relationships and intimacy and develop a program from that information.

Inclusion criteria for this study include adults over 18 years of age with Parkinson's disorder, Multiple Sclerosis, Huntington's disease, and Amyotrophic Lateral Sclerosis and their partners. The survey should take no longer than 25 minutes.

If you are interested in participating, the survey can be found at the following link: https://www.surveymonkey.com/r/OTintimacy

If you know anyone who meets criteria for inclusion and would be interested in taking the survey, I would greatly appreciate if you could forward them the survey link or my information!

If you have any questions, please contact me at:

Thank you for your time and I appreciate your interest in participation in this survey.

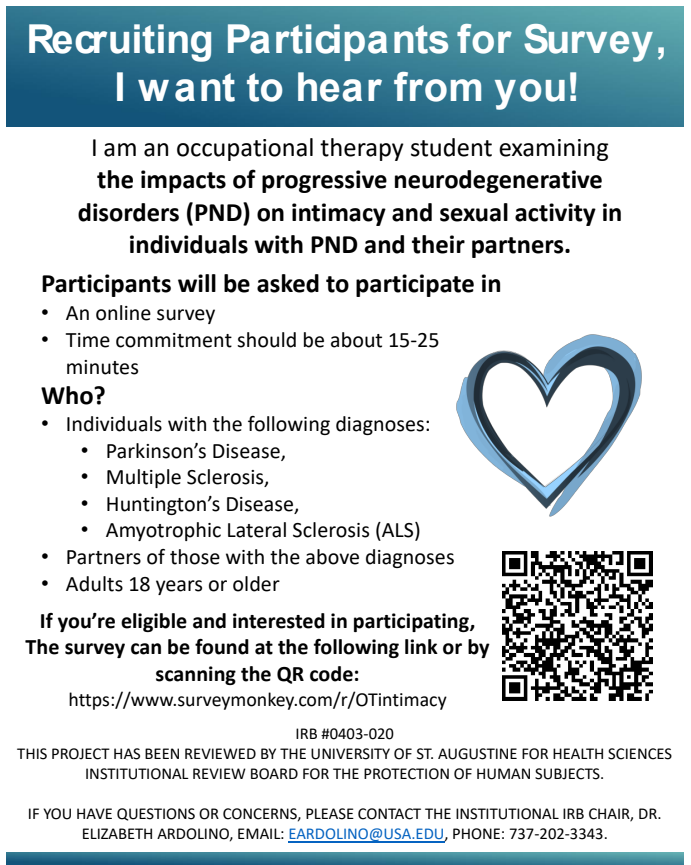

Condensed script with smaller character limit: Seeking participants for a study focusing on sex and intimacy for people with progressive neuromuscular disorders and their partners. If interested click the following link: https:/www.surveymonkey.com/r/OTintimacy (*insert diagnosis specific hashtags) 
*Diagnosis specific hashtags:

Multiple Sclerosis: multiplesclerosis, ms, msstudy, multiplesclerosisstudy

Parkinson's Disorder: parkinsonsdisorder, parkinsons, pd, pdstudy, parkinsonsstudy

Amyotrophic Lateral Sclerosis: amyotrophiclateralsclerosis, als, alsstudy, motorneurondisorder, mndstudy

Huntington's disease: huntingtonsdisease, hd, hdstudy, huntingtonsstudy

\section{Recruiting Participants for Survey, I want to hear from you!}

I am an occupational therapy student examining the impacts of progressive neurodegenerative disorders (PND) on intimacy and sexual activity in individuals with PND and their partners.

Participants will be asked to participate in

- An online survey

- Time commitment should be about 15-25 minutes

Who?

- Individuals with the following diagnoses:

- Parkinson's Disease,

- Multiple Sclerosis,

- Huntington's Disease

- Amyotrophic Lateral Sclerosis (ALS)

- Partners of those with the above diagnoses

- Adults 18 years or older

If you're eligible and interested in participating, The survey can be found at the following link or by scanning the QR code:

https://www.surveymonkey.com/r/OTintimacy
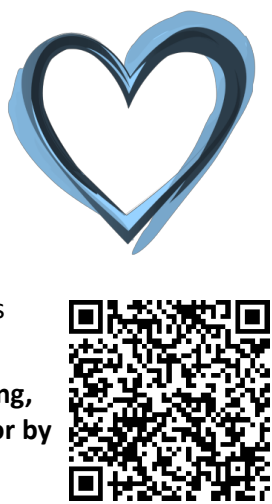

IRB \#0403-020

THIS PROJECT HAS BEEN REVIEWED BY THE UNIVERSITY OF ST. AUGUSTINE FOR HEALTH SCIENCES INSTITUTIONAL REVIEW BOARD FOR THE PROTECTION OF HUMAN SUBJECTS.

IF YOU HAVE QUESTIONS OR CONCERNS, PLEASE CONTACT THE INSTITUTIONAL IRB CHAIR, DR. ELIZABETH ARDOLINO, EMAIL: EARDOLINO@USA.EDU, PHONE: 737-202-3343. 


\section{Appendix D}

\section{Recruitment Script}

Hello everyone and thank you for welcoming me to attend your support group today. My name is Lindsay and I am an occupational therapy student. I am completing a research study for my doctorate project on the topic of how progressive neuromuscular disorders effect intimacy and sexuality. I am looking for people to take a survey that should take around 25 minutes. The survey will contain both open- and close-ended questions about relationships as well as what you would look for in a program addressing these topics. My hope is to further understand the impacts of these diagnosis on your relationships and intimacy and develop a program from that information. If you are interested in participating, please e-mail the group administrator and they will send you an e-mail containing the link to an online survey. I can answer anyone's questions about the project if you have any. Thank you! 


\section{Appendix E}

\section{Survey}

1. I consent to participate in this survey.

a. Yes

b. $\mathrm{No}^{*}$

2. Are you or your partner an individual with a diagnosis of a progressive neuromuscular disorder (Parkinson's disease, Huntington's disease, Multiple Sclerosis, or Amyotrophic Lateral Sclerosis)?

a. Yes, I am an individual with progressive neuromuscular disorder

b. Yes, I am a partner of an individual with progressive neuromuscular disorder

c. No, I am neither an individual with a progressive neuromuscular disorder or a partner*

3. I have/my partner has the following diagnosis:

a. Parkinson's disorder

b. Multiple Sclerosis

c. Huntington's disease

d. Amyotrophic Lateral Sclerosis (ALS)

e. None of the above*

*If participant selects this answer choice they will then be redirected to a page stating, "Thank you for your time and participations!" and will not be able to continue with the survey.

4. Age
a. 18-29 years old
b. 30-39 years old
c. 40-49 years old
d. 50-59 years old
e. 60-69 years old
f. 70-79 years old
g. 80 years or older
h. Decline to state

5. Age at your/your partner's diagnosis:

6. I identify my race as:*
a. Asian/Asian American
b. Black/African
c. Hispanic/Latinx
d. Native American
e. Pacific Islander
f. White
g. Prefer not to answer
h. Other (please specify)

7. I identify my faith/religion as:*
a. Buddhist
b. Catholic
c. Christian 
d. Jewish

e. Hindu

f. Muslim

g. Native American

h. Protestant

i. Inter/Non-denominational

j. No religion

k. Other (please specify)

*Participants will be able to choose multiple answers.

8. What is your gender?
a. Female
b. Male
c. Non-binary
d. Prefer not to say
e. Prefer to self-describe

9. Transgender is an umbrella term that refers to people whose gender identity, expression or behavior is different from those typically associated with their assigned sex at birth. Other identities considered to fall under this umbrella can include non-binary, gender fluid, and genderqueer - as well as many more.

Do you identify as transgender?
a. Yes
b. No
c. Prefer not to say

The following questions are going to ask about intimate relationships and sexual relationships. Commonly these are assumed to be the same. However, for the purpose of this survey intimacy will refer broadly to physical, emotional, experiential, and intellectual interactions with partners that do not have to require sexual activity (ex. dating, communicating, giving emotional support, vacationing). During the following section we will discuss intimate relationships and sexual relationships separately. We do not want to assume that everyone in a partnered relationship is sexual and that everyone who is sexual is in a relationship.

10. What is your sexual orientation?
a. Straight/Heterosexual
b. Gay or Lesbian
c. Bisexual
d. Prefer not to say
e. Prefer to self-describe

11. Relationship status

a. Partnered

b. Single and interested in partnership 
c. Single and not interested in partnership

12. If in a relationship, how long have you been in this relationship? If you are not in a relationship, type N/A.

13. Sexual relationship status

a. Sexually active

b. Not sexually active and interested in sexual relationships

c. Not sexually active and not interested in sexual relationships

14. If in an intimate relationship, how satisfied are you with your relationship?

a. Very satisfied

b. Satisfied

c. Neutral

d. Dissatisfied

e. Very dissatisfied

f. Not in a relationship

15. If sexually active, how satisfied are you with the sexual activity you engage in?
a. Very satisfied
b. Satisfied
c. Neutral
d. Dissatisfied
e. Very dissatisfied
f. Not sexually active

16. Do you feel your or your partner's diagnosis has affected your intimate relationship?

a. No

b. Yes, it has been positively affected

c. Yes, it has been negatively affected

d. Yes, it has been both positively and negatively affected

17. If yes, please describe how your/your partner's diagnosis has affected your intimate relationship:

18. Do you feel your or your partner's diagnosis has affected your sexual relationship?

a. No

b. Yes, it has been positively affected

c. Yes, it has been negatively affected

d. Yes, it has been both positively and negatively affected

19. If yes, please describe how your or your partner's diagnosis has affected your sexual relationship: 
20. Do you feel your or your partner's physical status has had an impact on your intimate relationship?

a. No

b. Yes, it has been positively affected

c. Yes, it has been negatively affected

d. Yes, it has been both positively and negatively affected

21. If yes, please describe how your or your partner's physical status has affected your intimate relationship:

22. What do you feel are your major supports to engaging in sexual activity?

23. What do you feel are your major supports to engaging in sexual activity?

24. What do you feel are your major barriers to engaging in sexual activity?

25. What do you feel are your major barriers to engaging in intimate relationships?

26. Please select the extent to which you agree/disagree with the following statement. I feel I can talk to my partner when feeling down:
a. Agree
b. Somewhat agree
c. Neither agree/disagree
d. Somewhat disagree
e. Disagree 
27. Do you feel satisfied in your ability to engage in activities which you find sexually satisfying?

f. Very satisfied

g. Satisfied

h. Neutral

i. Dissatisfied

j. Very dissatisfied

28. Do you feel satisfied in your ability to engage in activities which help satisfy your intimate relationship? (For example, dating, hobbies, flirting, giving emotional support, communicating, vacationing.) Very satisfied
a. Satisfied
b. Neutral
c. Dissatisfied
d. Very dissatisfied

29. Are you receiving any treatment from healthcare professionals in regard to your relationship?
a. Yes
b. No

30. If yes, please describe

31. Do you feel comfortable with seeking help from healthcare professionals regarding your relationship?
a. Yes
b. No

You are the expert in your life and diagnosis. These last questions are meant to help me understand what might help inform occupational therapists looking to address sexual activity and intimacy.

32. Given your situation, what would make sexual activity easier to engage in?

33. Given your situation, what would allow you to enhance your intimate relationship with your partner?

34. What do you think might help enhance other individuals with a similar diagnosis participation with sexual activity and intimacy? 
35. If you attended an event focused on enhancing your ability to engage in sexual activity and intimate relationships, what would you hope it would address?

36. Do you have any advice for how individuals with a similar diagnosis can engage in sexual activity or intimate relationships? 


\section{Appendix F \\ Outline for Sex and Intimacy Presentation \\ OCT 5425C Clinical Applications in Geriatrics}

What are we talking about today?

- Importance of addressing sex and intimacy

- OT's role

- Post-surgical interventions for common geriatric diagnoses

Why is addressing sex and intimacy important?

- Client-centered

- Improves quality of life

- Sex is an ADL

- Unaddressed by OT's and other healthcare professionals

Role of OT

- Activity analysis

- Adaptation

- Psychosocial interventions

- Medical management

- Education

- Communication skills

Intimacy

- IADL

- Examples of types of intimacy

o Physical

○ Mental

- Emotional

- Spiritual

Model Application

- Ex-PLISSIT

Joint Replacement

- Total hip replacement (THR)

○ Challenges

- Supports

- Total knee replacement (TKR)

$\circ$ Challenges

- Supports

Coronary Artery Bypass Graft (CABG)

- Challenges

- Supports

Laminectomy

- Challenges

- Supports

Cerebrovascular Accident (CVA)

- Challenges 
- Supports

Case study

- Break out groups

How can I incorporate sex and intimacy in practice?

- Introduction

- Enhance your own comfort

Resources

- Podcasts

- Websites

- Social Media

Please contact the author at lindsay.n.richards@gmail.com for presentation slides and permission to use. 


\section{Appendix G \\ Outline for Sex, Intimacy, and Assistive Technology Presentation \\ OCT 5330C OT Methods I: Assistive Technology}

What are we talking about today?

- Importance of addressing sex and intimacy

- OT's role

- Post-surgical interventions for common geriatric diagnoses

Why is addressing sex and intimacy important?

- Client-centered

- Improves quality of life

- Sex is an ADL

- Unaddressed by OT's and other healthcare professionals

Role of OT

- Activity analysis

- Adaptation

- Psychosocial interventions

- Medical management

- Education

- Communication skills

Intimacy

- IADL

- Examples of types of intimacy

○ Physical

- Mental

- Emotional

o Spiritual

Model Application

- Ex-PLISSIT

- Universal Design

- Sensory Integration

Assistive devices for pleasure

- Vibrating toes

- Dildo

- Anal toys

Assistive devices

- Strap on

- Masturbation sleeve or suction dildo

Assistive devices for positioning

- Sex swing and sex sling

- Sex stool

- Wedges

- Pillows 
- Spreader bars

Durable medical equipment during sex

- Shower chair or tub bench

- Grab bars

- Walker

Safe sex practices

- Hygiene

- Skin integrity

- Lubricants

- Communication

- STD prevention

Case study

- Break out groups

How can $I$ incorporate sex and intimacy in practice?

- Introduction

- Enhance your own comfort

Resources

- Podcasts

- Websites

- Social Media

Please contact the author at lindsay.n.richards@gmail.com for presentation slides and permission to use. 